\title{
Temperature Fields of the Droplets and Gases Mixture
}

\author{
Roman S. Volkov *(1), Ivan S. Voytkov and Pavel A. Strizhak \\ High Energy Physics Processes School, National Research Tomsk Polytechnic University, 30 Lenin Avenue, \\ Tomsk 634050, Russia; vojtkov12@mail.ru (I.S.V.); pavelspa@tpu.ru (P.A.S.) \\ * Correspondence: romanvolkov@tpu.ru; Tel.: +7-3822-701-777 (ext. 1945)
}

Received: 29 January 2020; Accepted: 23 March 2020; Published: 25 March 2020

\begin{abstract}
In this research, we obtain gas-vapor mixture temperature fields generated by blending droplets and high-temperature combustion products. Similar experiments are conducted for droplet injection into heated air flow. This kind of measurement is essential for high-temperature and high-speed processes in contact heat exchangers or in liquid treatment chambers, as well as in firefighting systems. Experiments are conducted using an optical system based on Laser-Induced Phosphorescence as well as two types of thermocouples with a similar measurement range but different response times $(0.1-3 \mathrm{~s})$ and accuracy $\left(1-5{ }^{\circ} \mathrm{C}\right)$. In our experiments, we inject droplets into the heated air flow (first scheme) and into the flow of high-temperature combustion products (second scheme). We concentrate on the unsteady inhomogeneous temperature fields of the gas-vapor mixture produced by blending the above-mentioned flows and monitoring the lifetime of the relatively low gas temperature after droplets passes through the observation area. The scientific novelty of this research comes from the first ever comparison of the temperature measurements of a gas-vapor-droplet mixture obtained by contact and non-contact systems. The advantages and limitations of the contact and non-contact techniques are defined for the measurement of gas-vapor mixture temperature.
\end{abstract}

Keywords: laser induced phosphorescence; gas-vapor mixture; high-temperature combustion products; droplets; temperature field; unsteady heat transfer

\section{Introduction}

Gas-vapor-droplet techniques are widely used in the industry (scrubbers, rectification towers, gas-vapor heat transfer agent generators, flame and thermal water treatment, etc.) [1-6]. Their popularity is explained by a relatively simple design, low material consumption, and high rate of heat exchange [1-5]. However, in each case, there are different specification requirements depending on the hardware and application purpose. In some cases, there is a demand for higher convective heat exchange (contact heat exchangers) and, in others, for higher vaporization (thermal water-treatment chambers and gas-vapor heat medium generators). In addition to the aforementioned practical industrial applications, the study of liquid spraying $[7,8]$ in a high-temperature environment is important for the design of efficient firefighting techniques [6,9-11].

The main barrier to the development of high-temperature gas-vapor-droplet techniques is the lack of knowledge on complex interdependent heat exchange and endothermic phase transformations occurring when droplets and vapor travel in high-temperature gas flows. Another important aspect of an efficient gas-vapor-droplet technique is the homogeneous heating or evaporation (depending on technical requirements) of droplets throughout the contact chamber. This is quite difficult to achieve due to massive thermal gradient and limited size of the chamber. This is why liquid droplets undergoing treatment do not evaporate completely during a single flow processing cycle. As a result, the efficiency of such installations, blocks, and units decreases significantly.

In the experiments [9-11] with contact measurement instruments (thermocouples), the temperature of combustion products decreased by 15 to $140{ }^{\circ} \mathrm{C}$ following a droplet injection during 1 to $5 \mathrm{~s}$, and the 
temperature of the gas-vapor mixture in the droplet trace remained low for up to $30 \mathrm{~s}$ [9]. Additional experiments were conducted for a certain variation range of the main parameters of droplets and heated gas blending [9-11]: initial gas flow temperature and velocity, droplet dimensions, and number and duration of injection events. The main result of the experiments [9-11] is the discovery of the main reasons behind the temperature drop in the droplet trace: droplet-to-gas convective heat exchange and low-temperature vapor injection due to rapid vaporization. Unfortunately, there is still no valid experimental data on temperature fields in the droplet trace, because most of the experiments are conducted using contact measurement techniques common to power engineering equipment. This approach demands a large number of thermocouples for simultaneous temperature registration in different sections of the droplet cloud. The more thermocouples are inserted into the flow, the heavier the disturbance. This is the main downside to tackling the problem using contact measurement. Thus, a new approach is required for the experimental study of heat and mass transfer in complex gas-vapor-droplet mixtures using non-contact techniques.

Recently, cross-correlation systems have become a frequent choice for the research of complex high-temperature heat and mass transfer. The annually increasing number of articles on phosphorus temperature survey and tracing particle imaging suggests that the aforementioned technique is of great interest and importance. The same conclusion can be made from the analysis of the results presented in [9-12].

The advancement in contact measurement techniques (thermocouple-based for the most part) is quite substantial. Still, this technique is labor-consuming and expensive in the case of temperature field measurement, especially if it is unsteady and inhomogeneous. Another limitation of thermocouples is their response time, which usually varies from several seconds to several dozens of seconds. High-temperature technologies normally involve thermocouples enclosed in protection tubes. This degrades their response time even more. Contact measurements are also inapplicable for temperatures of vapor-droplet mixtures, as droplets would settle on the thermocouple junction, thus lowering the temperature readings. Until all the liquid evaporates from the thermocouple junction, it is difficult to obtain reliable temperature readings, and in the case of continuous blending of droplet and gas media, it does not seem possible whatsoever. The minimum required number of instruments and their placement severely limits the applicability of the technique. The introduction of thermographic luminophores greatly simplified the temperature measurement and increased its accuracy and speed. It is viable to compare the experimental results obtained by the contact techniques (predominantly thermocouple measurement as the most widespread technique in actual industrial applications) presented in [9-12] with the Laser-Induced Phosphorescence (LIP) measurement results [13-16]. Such comparison would provide us with adequate adjusting factors for actual temperature prediction based on thermocouple readings.

The main energy strategy of Russia, China, India, and other rapidly developing countries is to establish a competitive power industry. This requires an increase in the resource efficiency of power systems through increasing the fuel consumption efficiency; implementing resource-saving technologies; investing in atmosphere friendly technologies; and reducing the external heat loss during power generation, transfer, and consumption. Today, the power industries of advanced countries are based on hydroelectric, nuclear, and thermal power stations. The most common are thermal power stations, even where other power generating technologies are in more favorable conditions to develop. The main heat loss of a thermal power plant is the flue gas loss. A gas-fired boiler loses $4-5 \%$ of heat through flue gases. At the same time, the amount of heat contained in vapor is within $12-13 \%$ of the gas combustion heat. It is possible to lower the heat loss at the combustion products heating the pulverized water in direct-contact economizers.

Flue gas recycling in contact heat exchangers improves the plant performance and lowers the NO and $\mathrm{CO}$ emission. The water heated in contact heat exchangers complies with sanitary regulations and standards. The most advanced heat transfer agents, especially the gas-vapor mixture, find more and more applications in contemporary industry: defrosting of granular materials, surface and reservoir 
treatment, construction, and agriculture. The advantages of this agent type are its high thermodynamic properties, fast response, and mobility of the corresponding installations.

Many researchers employ numerical simulation, in particular, of heat and mass transfer between liquid and gas. Today, these approaches have even greater potential due to a significant advancement in the information processing technology. Numerical simulation is an efficient tool for complex subject studies, which makes experimental research easier to accomplish. However, the result of numerical simulation does require an experimental confirmation. With the introduction of software and hardware instruments to implement panoramic optical techniques with high-speed video recording (see, for example, in [17-19]), it becomes possible to conduct such experiments to study multiphase flow, aerosol, and flame. The analysis of experimental results allows us to confirm the efficiency of liquid aerosol injection in the high-temperature gas-vapor-droplet technology. Pulsed injection provides more extensive heat transfer, lower liquid consumption, as well as quicker control over thermodynamic parameters. However, there is almost no information on the level of the temperature drop of combustion products after water aerosol injection, as well as on the lifetimes of lowered gas temperatures.

The purpose of this work is to study experimentally the variation rate of the gas-vapor mixture temperature field when droplets are blended with high-temperature combustion products using the non-contact technique of Laser-Induced Phosphorescence. Our paper [16] presents the results of experiments recording the temperatures of the gas-vapor mixture in the trace of a droplet, i.e., behind a single water droplet of the required size. It was a fundamental study linking three measurement techniques: Planar Laser Induced Fluorescence (PLIF) for measuring the droplet temperature, Particle Image Velocimetry (PIV) for measuring the velocity field of a gas-vapor mixture around a droplet, and LIP for measuring the temperature of a gas-vapor mixture around a droplet. In this paper, we present the experimental results focused on the droplets cloud, i.e., a large agglomerate of droplets. We use two techniques: LIP and PIV. Using the experimental results, we have, for the first time, determined the adjustment coefficients to be used in various contact and non-contact measurements. This gives the research findings their scientific novelty and practical value.

\section{Experimental Set-Up and Procedure}

\subsection{Experimental Set-Up}

In our experiments, we used a set-up schematically shown in Figure 1. The set-up allowed us to record gas-vapor-droplet flow temperature using both thermocouple and LIP-based non-contact measurement techniques. In our experiments, we used twin solid-state Nd:YAG laser Quantel Q-smart 4504 (wavelength $355 \mathrm{~nm}$, pulse frequency $10 \mathrm{~Hz}$, and maximum pulse energy $130 \mathrm{~mJ}$ ) to illuminate the flow. Optical set 5 was used to transform the laser beam into light sheet 6 with an opening angle of $10^{\circ}$, sheet thickness of approximately $0.6 \mathrm{~mm}$, and average width of $120 \mathrm{~mm}$ in the observation area. The air flow temperature was captured by two high-speed charged-coupled device (CCD) cameras Imager M-lite $2 \mathrm{M}$ (frame resolution $1920 \times 1280$ pix, frame rate $10 \mathrm{fps}$, digit capacity 12 bit) 1 and optical beam splitter 3 with a dichroic reflector (see Figure 1). Two Sigma DG $105 \mathrm{~mm}$ f/2.8 EX Macro lenses were used, supplied with two interference bandpass filters 2: $420 \mathrm{~nm}$ and $466 \mathrm{~nm}$. 


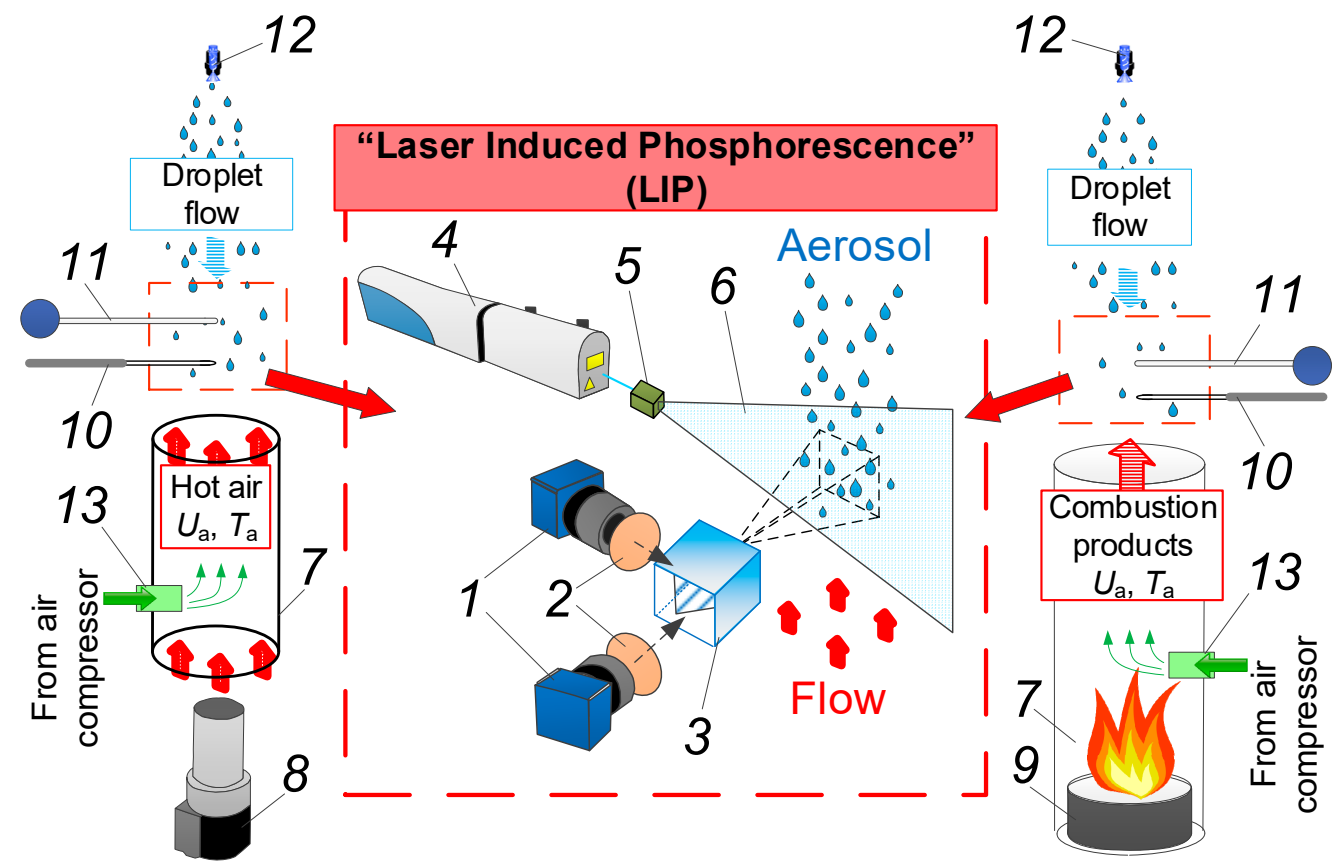

Figure 1. Scheme of experimental set-up: 1-video camera; 2-optical filter; 3-beam splitter; 4-Nd:YAG laser; 5-laser optics; 6-light sheet; 7—quartz cylinder; 8-air heater; 9—burner; 10—fast thermocouple; 11-slow thermocouple; 12-spraying nozzle; 13-position of BAM:Eu particles.

\subsection{High-Temperature Gas Flow}

The experiments are divided in two types when generating a high-temperature gas flow: (i) containing flue gases (combustion products) from liquid fuel combustion and (ii) heated air generated by a heater and an air compressor. The choice of these two types of gas media for this research comes from the conditions of promising gas-vapor-droplet technologies [1-5]. For instance, heated air is used in rectification towers and thermal treatment chambers, whereas combustion products or a mixture of flue gases and air are used in direct-contact heat exchangers. Combustion products contain a mixture of flue gases and ash particles. Therefore, temperature reduction and subsequent stabilization can have different characteristics. Therefore, we are considering both types of gas media in this study.

To generate a high-temperature combustion products flow similar to experiments $[9,10]$, we used the following elements (Figure 1); hollow cylinder of heat-resistant (up to $1800{ }^{\circ} \mathrm{C}$ ) quartz glass 7 ( $1 \mathrm{~m}$ height, $0.2 \mathrm{~m}$ outer diameter), burner 9 comprised of a hollow cylinder $(0.1 \mathrm{~m}$ height, $0.15 \mathrm{~m}$ and $0.19 \mathrm{~m}$ inner and outer diameter); TC-1 kerosene, a fuel with well-known and stable characteristics; and an exhaust system with an option to vary combustion product flow velocity $\left(U_{\mathrm{a}}\right)$ of up to $3 \mathrm{~m} / \mathrm{s}$. To generate the combustion products flow with a controlled temperature $\left(T_{\mathrm{a}}\right)$, we used the following procedure. Two-hundred-and-fifty milliliters of fuel was placed into the inner part of the burner and ignited using a piezoelectric lighter. A hollow glass cylinder was placed over the burner, and an upward flow of kerosene combustion products began to form in its inner chamber. Air was supplied into cylinder 7 through a hollow opening in the central part of burner 9. During the experiment, the flame height in cylinder 7 varied from 0.15 to $0.4 \mathrm{~m}$. The average temperature of the gas-vapor mixture, leaving the quartz channel, was controlled by varying the air consumption (by using an exhaust ventilation system) in the range of 100 to $500{ }^{\circ} \mathrm{C}$ [9]. To evaluate the component composition of combustion products in the experiments, we used a Testo- 340 gas analyzer with the following measurement ranges; $\mathrm{O}_{2}$ : 0-25\%; CO: 0-10,000 ppm; NO: 0-3000 ppm; $\mathrm{NO}_{\mathrm{x}}$ : 0-300 ppm; $\mathrm{SO}_{2}$ : 0-5000 ppm; accuracy: $\mathrm{O}_{2}: \pm 0.3 \%$; $\mathrm{CO}, \mathrm{CO}_{2}, \mathrm{NO}, \mathrm{SO}_{2}$ : from $\pm 5 \%$ to $\pm 10 \%$ ). The main concentrations were measured before the aerosol injection experiments started. The methods used in the experiments 
are similar to those described in [9]. Thus, we determined the fraction of components, in particular, $\mathrm{CO}_{2}, \mathrm{CO}, \mathrm{NO}_{\mathrm{x}}, \mathrm{NO}, \mathrm{SO}_{2}$, and $\mathrm{O}_{2}$. Table 1 presents average concentrations of components in kerosene combustion products, obtained through measurements in this study. We also compared them with the data from the work in [9].

Table 1. Average concentrations of $\mathrm{CO}_{2}, \mathrm{CO}, \mathrm{NO}_{\mathrm{x}}, \mathrm{NO}, \mathrm{SO}_{2}$, and $\mathrm{O}_{2}$ in kerosene combustion products, as well as data from the work in [9].

\begin{tabular}{ccccccc}
\hline \multirow{2}{*}{ Type of Flammable Liquid } & \multicolumn{7}{c}{ Component Concentration } \\
\cline { 2 - 7 } & $\mathbf{O}_{\mathbf{2}, \boldsymbol{\%}}$ & $\mathbf{C O}_{\mathbf{2}}, \mathbf{\%}$ & $\mathbf{C O}, \mathbf{\%}$ & $\mathbf{N O}, \mathbf{\%}$ & $\mathbf{N O}_{\mathbf{x}}, \mathbf{\%}$ & $\mathbf{S O}_{\mathbf{2}}, \mathbf{\%}$ \\
\hline Kerosene & 12.02 & 6.21 & 0.13438 & 0.0038 & 0.0041 & 0 \\
Kerosene [9] & 11.71 & 6.79 & 0.12567 & 0.0044 & 0.0046 & 0.00013 \\
Industrial ethanol [9] & 14.9 & 4.4 & 0.0577 & 0.0017 & 0.0018 & 0 \\
Acetone [9] & 15.68 & 3.87 & 0.0308 & 0.0027 & 0.00287 & 0 \\
Gasoline [9] & 12.9 & 5.85 & 0.1585 & 0.0036 & 0.0039 & 0 \\
\hline
\end{tabular}

We found (Table 1) that the concentrations of the main components in kerosene combustion products, measured in this study, are close to the results from those in [9]. It is also clear that for the group of flammable liquids under study [9], the concentrations of the main combustion product components are generally quite close. Moreover, these concentrations are within the allowable level for typical boiler plants (in accordance with the Russian standard GOST R 50831-95). Thus, it is safe to say that using kerosene combustion products in the experiments makes it possible to simulate the conditions close to real technologies [1-5].

To generate a heated air flow for the second kind of experiments, we used hollow cylinder 7 made of heat-resistant (up to $1800^{\circ} \mathrm{C}$ ) quartz glass $(0.4 \mathrm{~m}$ height, $0.2 \mathrm{~m}$ outer diameter) and air heater 8 to form an air flow with a controlled temperature in the range of 100 to $300^{\circ} \mathrm{C}$. A Leister LE $5000 \mathrm{HT}$ heater (Leister Technologies AG, Kaegiswil, Sweden) with a temperature range of $T_{\mathrm{a}}=100-600^{\circ} \mathrm{C}$ was used for heating. A Leister CH 6060 compressor (Leister Technologies AG, Kaegiswil, Sweden) with a flow rate of $U_{\mathrm{a}}=0-5 \mathrm{~m} / \mathrm{s}$ generated the air flow. The accuracy of parameter setting was $\pm 1{ }^{\circ} \mathrm{C}$ for temperature and $\pm 0.02 \mathrm{~m} / \mathrm{s}$ for flow velocity.

\subsection{Droplets}

To generate a sprayed water flow, we used a system comprised of a water reservoir, feeding channel, and spraying nozzle 12. The nozzle was the same as in [20,21]. To determine the droplet flow characteristics (droplet velocity $U_{\mathrm{d}}$ and droplet radius $R_{\mathrm{d}}$ ), we used a panoramic optical system. The initial droplet flow velocity $U_{\mathrm{d}}$ was measured via the PIV optical technique [22]. The initial droplet radius in the sprayed flow was measured via the SP technique [23]. Nozzle 12 generated droplets with a radius $R_{\mathrm{d}}=0.06-0.18 \mathrm{~mm}$. The initial droplet flow velocity was $2-3 \mathrm{~m} / \mathrm{s}$ throughout the series of experiments. The volume concentration of droplets in the sprayed flow $\gamma_{\mathrm{d}}$ was $3.8 \cdot 10^{-2} \mathrm{l} / \mathrm{m}^{3}$. It was chosen as an average value from the practical applications mentioned in the Introduction and the experiments in $[9,10]$.

When processing the flow images obtained by SP, we divided all the droplets in each frame into $m$ groups. For each group, we calculated the mean radius $\left(R_{\mathrm{dm}}\right)$ and number $(n)$ of droplets in the group, volume $V_{\mathrm{m}}=n \cdot 4 / 3 \cdot \pi \cdot R_{\mathrm{dm}}{ }^{3}$. Then, we determined the notional volume of the observation area: $V_{\mathrm{a}}=x \cdot y \cdot \eta$. After that, we calculated the volume concentration of droplets in the observation area for each frame: $\gamma_{\mathrm{d}}=V_{\mathrm{m}} / V_{\mathrm{a}}$. If the droplet concentration deviated from the values $\gamma_{\mathrm{d}} \approx 3.8 \cdot 10^{-2} \mathrm{l} / \mathrm{m}^{3}$ by more than $10 \%$, the experiment was disregarded in the subsequent analysis. During the experiments estimating $\gamma_{\mathrm{d}}$ and $R_{\mathrm{d}}$, we determined that the spray event duration $\left(t_{\mathrm{imp}}\right)$ did not affect the flow characteristics. Moreover, at the initial (lasting less than $0.15 \mathrm{~s}$ ) and final (lasting less than $0.1 \mathrm{~s}$ ) stages, the $\gamma_{d}$ values can deviate from the mean ones by $15-20 \%$. This effect was not taken into consideration when analyzing the results. 
All the said parameters $\left(\gamma_{\mathrm{d}}, U_{\mathrm{d}}\right.$, and $\left.R_{\mathrm{d}}\right)$ were measured in the same area that was further used to measure the gas-vapor mixture temperature (Figure 1). During the experiment, water was repeatedly sprayed into the inner portion of cylinder 7 , towards the high-temperature combustion products or heated air flow. Spray event duration $\left(t_{\mathrm{imp}}\right)$ varied in the range of 1 to $5 \mathrm{~s}$. Spraying was repeated every $30 \mathrm{~s}$. An electronic timer of $0.1 \mathrm{~s}$ time increment was used for time recording. Each experiment involved 10 to 15 injections. At least 10 experiments were conducted for each set of initial parameters $\left(\gamma_{\mathrm{d}}, t_{\mathrm{imp}}, R_{\mathrm{d}}, U_{\mathrm{d}}\right.$, and $\left.U_{\mathrm{a}}\right)$.

Each experiment consisted of the following steps; (i) a high-temperature gas flow was generated as described in Section 2.2; (ii) for combustion products, injection of water spray into the observation area started after $250 \mathrm{~s}$ (the time needed for the required temperature level to be established in cylinder 7); for heated air, injection of water spray into the observation area started after the temperature became steady; (iii) simultaneously with the first droplet injection, we started the continuous recording of gas-vapor mixture temperature at the cylinder input using fast (10) and slow (11) thermocouples (see Section 2.4) connected to a high-speed analog input card (0.1 s sampling step), as well as via the LIP system (see Section 2.5).

\subsection{Thermocouple Measurement}

Both the gas and gas-vapor-droplet environment temperature during the experiments was measured with two different thermocouples (Figure 2): slow thermocouple 11 (Oven, Moscow, Russia) (K-type, measurement temperature range 0 to $1200{ }^{\circ} \mathrm{C}$, junction diameter $1 \mathrm{~mm}$, response time $3 \mathrm{~s}$, accuracy $\pm 5^{\circ} \mathrm{C}$ ); fast thermocouple 10 (S-type, measurement temperature range 0 to $1200{ }^{\circ} \mathrm{C}$, junction diameter $0.25 \mathrm{~mm}$, response time $0.1 \mathrm{~s}$, accuracy $\pm 1{ }^{\circ} \mathrm{C}$ ) (Figure 1). Sensors of both thermocouples were placed at a $2-3 \mathrm{~mm}$ distance from each other in the center of the observation area (Figure 1). The thermocouples were connected to the National Instruments 9213 analog input card. The sampling rate was $0.5 \mathrm{~s}$. Thermocouple readings were loaded to a PC, where the variation trend of the measured environment temperature was plotted.

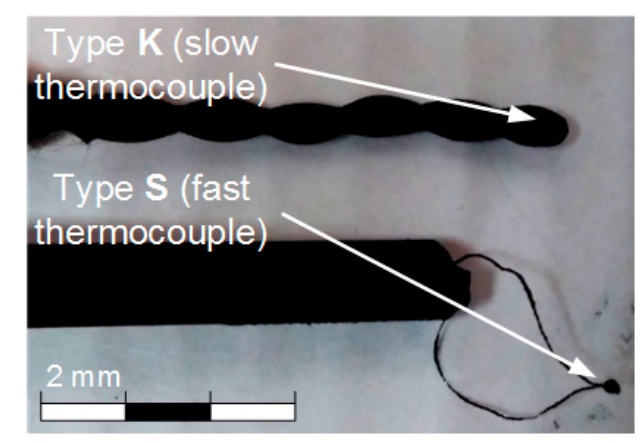

Figure 2. Thermocouples used in the experiments.

Notably, the presence of soot particles and water vapors in the flow can affect the characteristics of measurement. That is why we used a thermocouple with a very fast response time in our experiments. This enabled us to minimize the influence of the said factors. A thermocouple has a thin protection sheath to protect it from moisture and solid soot particle impact. However, we removed it in these experiments to improve the thermocouple response time. We calibrated the data of thermocouples in a heated air flow, using a specialized set-up and varying the temperature in a wide range $\left(20-600^{\circ} \mathrm{C}\right)$. The set-up consisted of a vertically positioned hollow quartz-glass cylinder channel $96 \mathrm{~mm}$ in the inner diameter. A heated air flow was generated inside the cylinder. For that, we used a LEISTER CH 6060 compressor with a flow rate of $0-5 \mathrm{~m} / \mathrm{s}$ and a LEISTER LE $5000 \mathrm{HT}$ heater with a temperature range of 20 to $600{ }^{\circ} \mathrm{C}$. The accuracy of temperature setting was $\pm 1{ }^{\circ} \mathrm{C}$. A fast-response thermocouple was introduced through an aperture in the cylinder, using a motorized manipulator; the thermocouple readings were recorded with an NI 9219 analog input module with a time increment of 
$0.5 \mathrm{~s}$. The deviations of the thermocouple readings from the established value did not exceed $1.5^{\circ} \mathrm{C}$ within the whole temperature range. Moreover, heated air was not found to affect the integrity of the thermocouple junction not covered with a protection sheath. The condensate and vapors can have some influence, but it can be disregarded when analyzing the results of a series of experiments. A similar conclusion can be made when analyzing the influence of solid soot particles. After each experiment in a series, we picked the thermocouple junction out of the channel and wiped it with a cloth. The thermocouples were introduced into the channel again for measurement after they cooled down at room temperature for 10 minutes. In particular, we conducted all the experiments in sets of 5 or 6 , and then calculated the confidence interval. All the measured values lie within this interval, and they are presented further in the figures (in Section 3).

\subsection{LIP Measurement Technique}

The Laser-Induced Phosphorescence (LIP) technique is not new. It is based on the phosphorescence of specialized particles illuminated by near-UV radiation [13-15,24-27], and is actively used to diagnose the temperature of gas media [25,27], droplets, and layers of liquids [28,29], as well as aerosol clouds [30]. Abram, C. et al. [31] present the results of temperature measurement using LIP and different luminophores: BAM:Eu, $\mathrm{ZnO}: \mathrm{Zn}, \mathrm{ZnO}: \mathrm{Ga}$, etc. The properties of these particles and their validity ranges were determined. The dependence of phosphorescence intensity on temperature was established. The results from the works in [27-31] correspond mainly to single-phase flows and media. There are no research findings for the processes, characterized by the mixing of the gaseous and liquid media. At the same time, the stability of some types of particles, both in gas and in liquid, allows us to assume that LIP can be used to diagnose the temperature of multiphase media.

To evaluate the temperature distribution of the gas-vapor flow, we used LIP [24-26]: a non-contact laser thermal mapping technique for gas and vapor temperature diagnostics. We recorded the thermal emission from thermographic particles under the laser excitation by a $355 \mathrm{~nm}$ wavelength beam. We used special phosphorescent particles of $\mathrm{BaMgAl}_{10} \mathrm{O}_{17}:$ Eu powder (BAM:Eu) $[24,25]$ (particle dimensions 6-8 $\mu \mathrm{m}$ ). The upper operating temperature range of these particles-thermal degradation threshold-is 550-600 ${ }^{\circ} \mathrm{C}[24,25]$. Two CCD video cameras equipped with interference filters ( $420 \pm 10 \mathrm{~nm}$ and $455 \pm 10 \mathrm{~nm}$ ) were used for recording. BAM:Eu particles absorb laser radiation with a wavelength of $355 \mathrm{~nm}$. The maximum of the BAM:Eu emission spectrum falls between 440 and $450 \mathrm{~nm}$. With a gas medium temperature increase, the maximum of particle emission spectrum almost does not relocate but we observe the left boundary of the spectrum shift towards lower wavelengths $(420-380 \mathrm{~nm})$. The right side of the spectrum shifts as well (Figure 3a). The emission spectrum for different temperatures (Figure 3a, left) of the BAM:Eu particles that we used is described in [24-26]. Here, the temperature of the flow depends on the emission intensity ratio of the left $(420 \mathrm{~nm})$ and right $(450 \mathrm{~nm})$ sides of the emission spectrum. This ratio increases with a rise in the flow temperature (Figure 3a, right). Thus, the use of optical filters with two different wavelengths 2 (Figure 1) allowed us to register the spectral shift of BAM:Eu particles emission when their temperature changed.

Before the beginning of the experiments, BAM:Eu were dried in a muffle furnace at $100{ }^{\circ} \mathrm{C}$ for 120 minutes to prevent the particles from clumping and to ensure a more even seeding of the air flow. To seed the air flow with BAM:Eu particles, we used an air compressor (24 1 reservoir, 1.2 MPa maximum pressure). Tracer particles were placed into an elbowed input duct fixed on the side of the channel (Figure 1). The air from the compressor under a pressure of $200 \mathrm{kPa}$ was fed through the duct for 5 seconds, so that all the tracer particles were injected into the air flow. The mass of the BAM:Eu particle sample injected into the air flow was approximately $1.5 \mathrm{~g}$ for each event. This is the experimentally defined mass, sufficient for uniform seeding of the air flow. Each experiment involved 3-5 consecutive injection events. An air extraction duct $150 \mathrm{~mm}$ in diameter, provided with a fine-mesh filter, able to absorb particles as small as $0.1 \mu \mathrm{m}$, was placed above the gas flow channel. The heated air flow was collected by the extraction fan, and the tracer particles were absorbed by the filter. Figure $3 \mathrm{~b}$ 
shows a typical video frame with BAM:Eu particles moving in an air flow (before it was processed in the DaVis software).
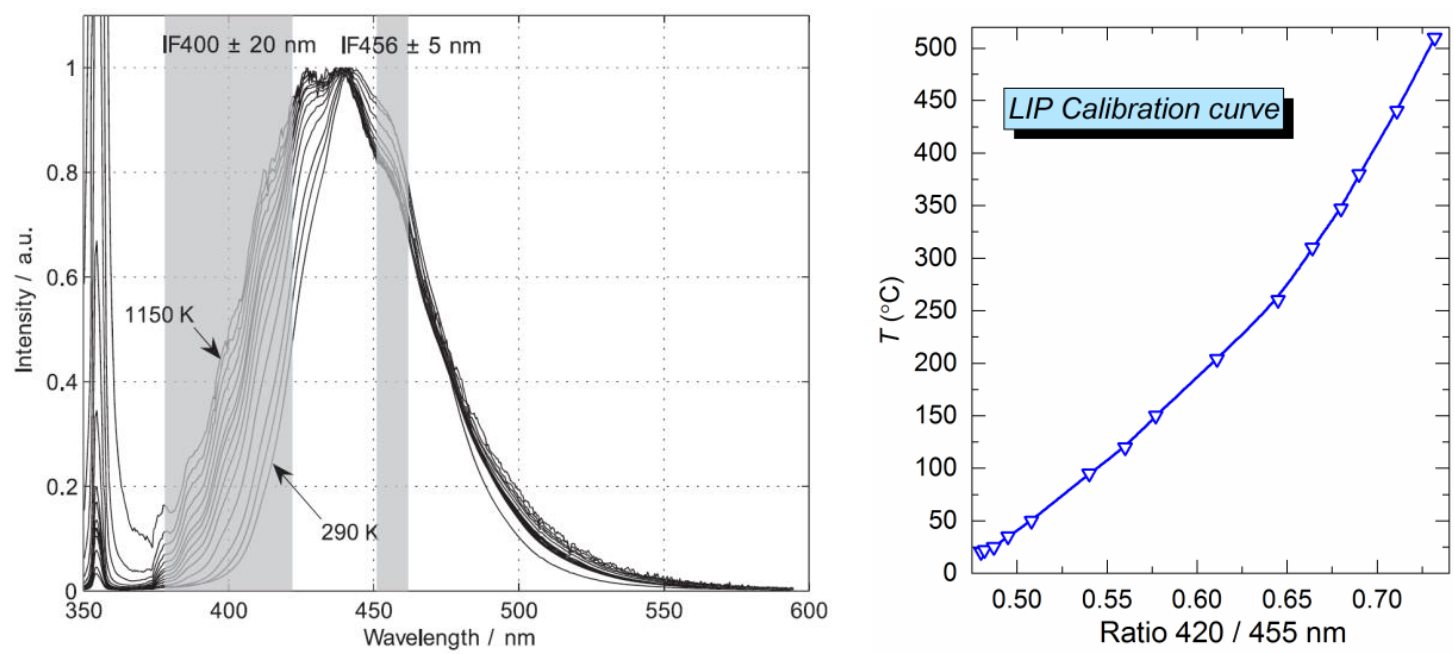

(a)
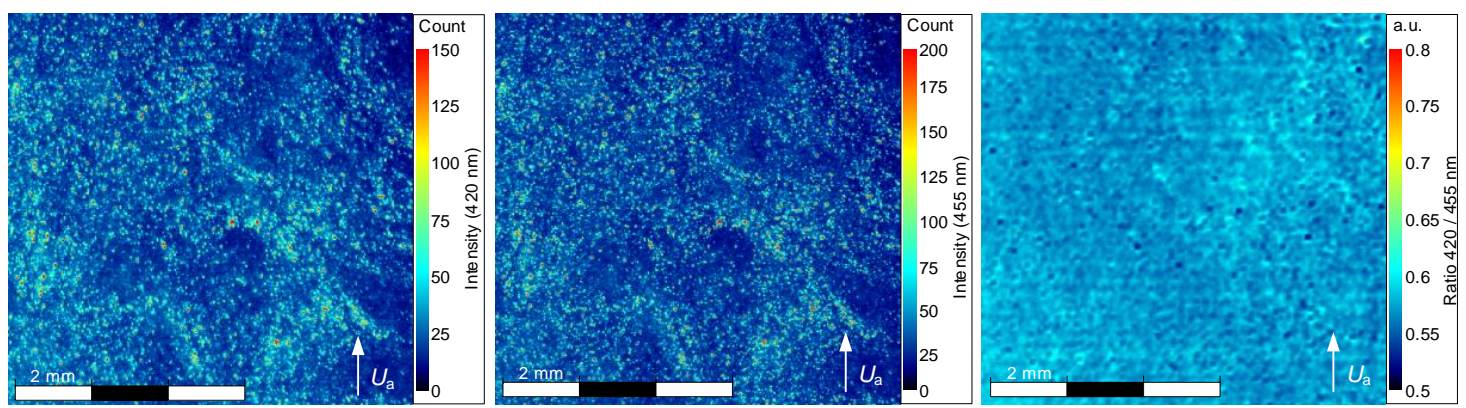

(b)
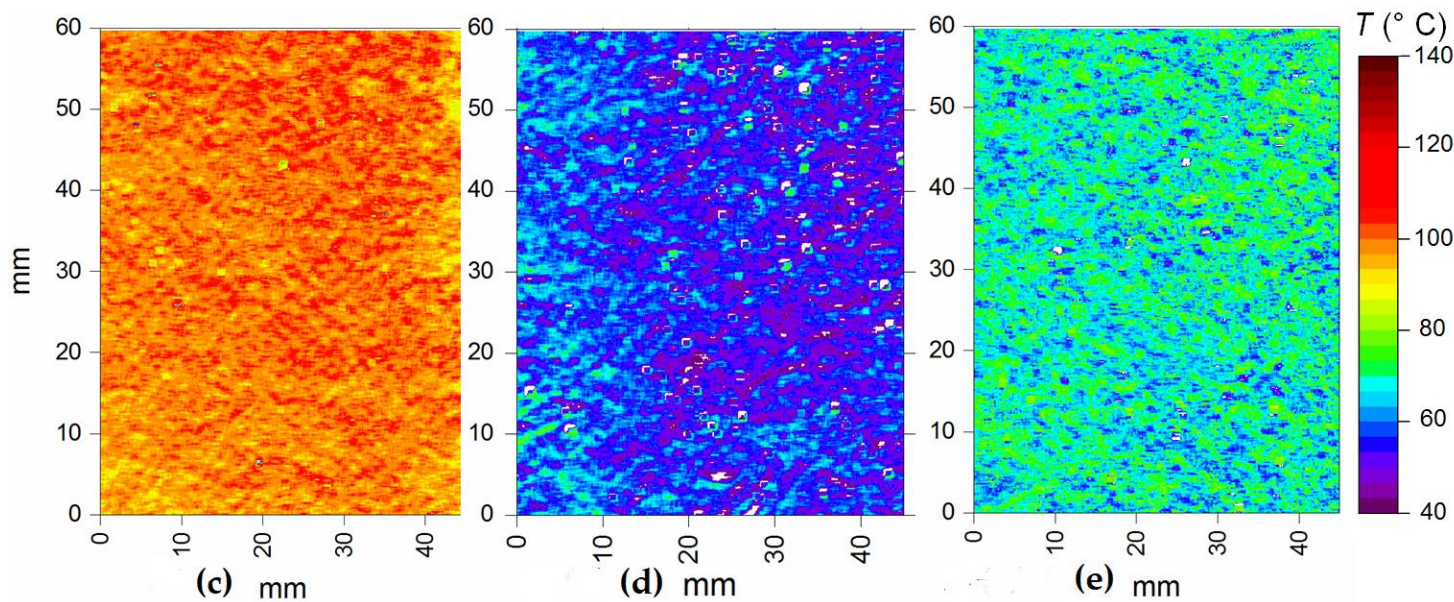

Figure 3. The emission (left) spectrum [26] and calibration (right) curve (a); video frame of BAM:Eu particles before being processed (b); typical airflow temperature field without droplets (c), air flow (d) and combustion products flow (e) after droplets pass-through obtained by Laser-Induced Phosphorescence (LIP) technique (for $T_{\mathrm{a}} \approx 200^{\circ} \mathrm{C}$ ).

For optical calibration of the measurement system (correcting and comparing images from two cameras), a flat calibration target was used with an in-line array of markers, $2 \mathrm{~mm}$ in diameter located $5 \mathrm{~mm}$ away from each other. We used the DaVis software (LaVision Inc., Göttingen, Germany) for 
experimental image processing and temperature field recovery. Image processing comprised a series of consecutive operations according to the conclusions made in [24,25]. A background was subtracted from each initial image obtained. The image was then calibrated using the calibration target image. A series of software filters were applied to remove noise, to mask areas with no tracer particles, and to smooth the luminous intensity of tracers. The fluorescence gradient in the image was adjusted with White Image Correction, and a temperature field was plotted based on the analysis of the emission intensity from two optical filters.

The LIP technique experiments were conducted in two stages: The first one is the temperature calibration of the system in the absence of sprayed flow in the observation area. For each standalone experiment, the LIP temperature field could only be recorded while BAM:Eu particles were in the observation area (1.5-2 s), which is not enough time to record the whole blending process. That is why the second stage included a series of experiments, starting with the initial droplet flow injection (recording initiated at $0 \mathrm{~s}$ ), and then with $2 \mathrm{~s}$ increment until the temperature recovery relative to the undisturbed gas flow.

When conducting their experiments, the authors focused on such matters as the power fluctuations of the Nd:YAG laser and the concentration of the thermographic indicator in the measurement area [26,27]. The experimental results have shown that, when the laser power ranges from 70 to $130 \mathrm{~mJ}$, the BAM:Eu emission changes proportionally. However, the emission intensity ratio of BAM:Eu $(420 / 450 \mathrm{~nm})$ remains the same and does not exceed the systematic error of the technique. The result obtained is in good agreement with the results from the work in [27], where the authors explored the impact of laser power on the emission intensity and heating of thermographic phosphor particles.

On the other hand, for reliable measurements, it is important to maintain the optimal concentration of BAM:Eu particles in the measurement area. The relative volume concentration $\left(\gamma_{\mathrm{p}}\right)$ of BAM:Eu particles in a frame (Figure 3b) was derived indirectly from the intensity of the laser radiation emitted by the particles. As a criterion to estimate $\gamma_{p}$, we used the ratio of the total area of BAM:Eu particles in a frame $\left(S^{*}\right)$, derived from the binarization threshold, to the observation area size $\left(S_{0}=x \cdot y\right): \gamma_{\mathrm{p}}=S^{*} / S_{0}$. Moreover, experiments have established that the average fluorescence of droplets did not exceed 25-30 intensity counts when they were on screen. At the same time, the fluorescence of BAM:Eu particles was 10-12 times higher and reached 100-170 intensity counts for the left side of the emission spectrum $(420 \mathrm{~nm})$ and $160-220$ intensity counts for the right side $(450 \mathrm{~nm})$ of the same spectrum. Thus, by specifying the binarization threshold above the luminous intensity of droplets, we discarded droplets from analysis so that they did not affect the determination of $\gamma_{\mathrm{p}}$. When constructing temperature fields, we only considered the experimental frames where the relative concentration of BAM:Eu particles $\gamma_{p}$ was within $0.05-0.1$. When $\gamma_{p}$ was varied within the said range, temperature deviations did not exceed $1.5^{\circ} \mathrm{C}$.

The goal of the first stage was to obtain a calibration curve (Figure 3a, on the right) - air flow temperature versus relative fluorescence of BAM:Eu particles. The procedure is similar to the one described in $[17,18]$. For this purpose, a series of experiments were conducted, capturing the particle images in the air flow when increasing its temperature from 20 to $500^{\circ} \mathrm{C}$. The choice of the temperature range is primarily conditioned by the thermal degradation threshold of the thermographic particles used. There are several types of BAM:Eu with different threshold temperatures ranging from $600{ }^{\circ} \mathrm{C}$ to $800{ }^{\circ} \mathrm{C}$ [19]. The upper temperature threshold of the $\mathrm{BaMgAl}_{10} \mathrm{O}_{17}:$ Eu particles used in the experiments is $600{ }^{\circ} \mathrm{C}$. However, as the temperature fluctuations of the combustion products (Section 3.2) often exceed $60-80^{\circ} \mathrm{C}$, we chose $500^{\circ} \mathrm{C}$ as the upper limit for the experiments. At least three experiments were conducted for each point. In each experiment, an average between readings from two thermocouples installed at the input and output of the small-size observation area was taken as the flow temperature. The images obtained were processed as described previously, except the temperature field plotting (this stage was excluded). Instead, as the final stage, we used the Temperature Calibration function to plot a calibration curve from the points obtained (Figure 3a, left). At the same time, the calibration curve (Figure 3a, right), as in most 2-color methods, was plotted by comparing the emission intensities 
of the left and right sides of the spectrum (Figure 3a, left). That is, we found the emission intensity ratio of BAM:Eu (420 nm/450 nm). Then, for each ratio, we took the flow temperature measured by a Type $\mathrm{K}$ thermocouple in the course of video recording. The data obtained was presented as the calibration curve (Figure 3a, left). The experimental data scattering (emission intensity ratio of BAM:Eu: $420 \mathrm{~nm} / 450 \mathrm{~nm}$ ) on the calibration curve did not exceed $3 \%$ for the identical flow temperatures.

The second stage involved temperature recording in a gas-vapor trace of droplet flow (Figure 3c-e). To generate a droplet flow in the observation area, we used the hardware described in Section 2.3. At least three experiments were conducted for each different water injection duration $\left(t_{\text {imp }}\right)$. After the recording was finished, frames with the even distribution of tracer particles were selected to match the tracer distribution in the images obtained during the temperature calibration. These second-stage images were processed as described earlier. At the final stage of processing, instantaneous temperature fields of the airflow were plotted with the help of the calibration curve obtained at the earlier stage of the experiments.

There is some nonuniformity of the temperature fields in Figure $3 c-e$, connected with an uneven concentration of BAM:Eu particles in the flow. There are regions where the concentration of phosphorescent indicator particles is small or there are none of them. This creates a noisy picture, when the results are processed. To smooth the temperature field, we used Linear Smoothing Filter, averaging the data in the region $3 \times 3 \mathrm{px}$ in size. When processing the LIP measurement data, this type of filter was used straight after finding the Ratio $420 / 455 \mathrm{~nm}$. This allowed us to take into consideration the changes in the ratio $420 / 455 \mathrm{~nm}$ due to smoothing. Thus, the calibration curve (Figure $3 \mathrm{~b}$ ) already took into account the smoothing, and this process $(3 \times 3$ Linear Smoothing Filter) had absolutely no effect on the temperature of the resulting temperature field.

In the preparation and adjustment of the experimental technique, an important issue was the influence of aerosol droplets on the reliability of temperature measurement using LIP. In particular, the results from $[32,33]$ show that the effects of absorption and, on the contrary, dissipation of laser ultraviolet signal can lead to additional errors when determining the flow temperature. Thus, e.g., Lee, H. et al. [32] show that a phosphorescent signal can be generated even in the areas that are not seeded with BAM:Eu particles. This happens due to multiple dissipations in the areas in front of or behind the jet under study [32]. Therefore, it was necessary to conduct additional experiments.

First, the coefficients of water and water vapor absorption were analyzed. According to the results from the work in [34], the water absorption coefficient in the range of wavelengths 355 to $465 \mathrm{~nm}$ varies from 0.00442 to $0.01137 \mathrm{~m}^{-1}$. Given that the maximum distance, covered by the laser sheet in the measurement area, is comparable to the diameter of the quartz channel $(0.1 \mathrm{~m})$, the maximum absorption will not exceed $0.12 \%$, even when the droplet concentration is at maximum. According to the data from HITRAN website, water vapors, forming as a result of droplet evaporation, absorb light mainly in the near-IR range (over $900 \mathrm{~nm}$ ). Thus, the main reason for error, caused by aerosol droplets, can be the dissipation of laser radiation by them.

To evaluate the influence of aerosol droplets on the results of LIP measurement, we conducted an experiment, using an air flow generation setup (Figure 1) at $T_{\mathrm{a}} \approx 25^{\circ} \mathrm{C}$. At the first stage, the air temperature was measured without aerosol flow injection, at the second stage, with aerosol droplets in the recording area. The spray event duration in the experiment was $t_{\text {imp }} \approx 3 \mathrm{~s}$. We calculated temperature fields and compared them. Abram, C. et al. [25] established that the intensity ratio $(420 / 455 \mathrm{~nm})$ in the recording area in two of the cases under consideration differs by no more than $1.5 \%$, which does not exceed the systematic error of LIP for $25^{\circ} \mathrm{C}$ The experimental results also indicate that the local areas, corresponding to water droplets, have much lower ( 2 to 3 times) intensity than the areas containing BAM:Eu particles. These areas were masked before the temperature field plotting. When analyzing and comparing the final temperature fields, it was established that at a volume concentration of droplets $\gamma_{\mathrm{d}} \approx 3.8 \cdot 10^{-2} \mathrm{l} / \mathrm{m}^{3}$, their presence does not considerably deviate the temperature field. The difference in the mean temperature recorded with and without aerosol droplets did not exceed the error of LIP technique for $25^{\circ} \mathrm{C}(\sim 1.7 \%$ [25]). Moreover, the moment of aerosol 
injection, just as the whole process of its movement in the reversed gas flow, takes $1-5 \mathrm{~s}$, which is much less than the duration of the experiment (15-20 s). These estimates make it possible to conclude that it is reasonable to use the newly developed measurement technique.

\subsection{Experimental Data Processing}

The temperature distribution (LIP measurement) and temperature trend (thermocouple measurement) obtained were processed similarly to $[20,21]$ to determine the following parameters; $\Delta T_{\mathrm{a}}$ : temperature drop of combustion products or air in the trace of droplet flow relative to its initial value, ${ }^{\circ} \mathrm{C}$; $\tau$ : low (relative to the initial) gas temperature lifetime in the trace of droplet flow, s. Parameter $\tau$ describes the time from the point when the temperature of combustion products started dropping, $\tau_{1}$ (recording initiation at $0 \mathrm{~s}$ ), until the time of the complete recovery of its initial value, $\tau_{2}$. The thermal trace of a droplet is defined as an area in the wake of droplet flow with a temperature at least $10^{\circ} \mathrm{C}$ lower than the initial $T_{\mathrm{a}}$.

Unlike in $[20,21]$, for each of the measurement techniques in this research, we additionally calculated temperature fluctuation $\delta T$ as a difference between maximum $\left(T_{\max }\right)$ and minimum $\left(T_{\min }\right)$ temperature readings in a single experiment (i.e., experimental temperature dispersion at identical initial conditions). We also calculated the difference $(\Delta T)$ between the thermocouple $\left(T_{\text {Therm }}\right)$ and LIP $\left(T_{\text {LIP }}\right)$ measurement results. To do this, we compared the calculated mean averages from each series of experiments for thermocouple measurement to similar parameters derived from the processed LIP measurement data.

\section{Results and Discussion}

Presented below are the results of the experimental evaluation of gas and gas-vapor environment temperature. We analyzed the difference between the experimental results of the high-speed optical measurement (LIP) and thermocouple measurements typical of industrial power installations. Also, the results obtained are generalized with respect to the techniques, data, and conclusions from the work in [21]. The experiments have also shown that the differences between the temperature measurements in the experiments with air flow and combustion products are significant. They show essentially different effects and patterns. Therefore, we discuss the results for flows of different gases separately (see Sections 3.1 and 3.2).

\subsection{Hot Air Flow}

Figure 4a shows 3D surfaces illustrating the air flow temperature fields obtained by LIP. Maximum temperature fluctuations over time for the LIP technique are shown as $\delta$ T. They are approximately $11^{\circ} \mathrm{C}$ for $T_{\mathrm{a}}=100{ }^{\circ} \mathrm{C}$, approximately $20^{\circ} \mathrm{C}$ for $T_{\mathrm{a}}=200{ }^{\circ} \mathrm{C}$, and approximately $47^{\circ} \mathrm{C}$ for $T_{\mathrm{a}}=300{ }^{\circ} \mathrm{C}$. That means, assuming the measured temperature is stationary, the LIP technique accuracy is approximately $\pm 5.5^{\circ} \mathrm{C}$ at $100{ }^{\circ} \mathrm{C}$, approximately $\pm 10{ }^{\circ} \mathrm{C}$ at $200{ }^{\circ} \mathrm{C}$, and approximately $\pm 23.5^{\circ} \mathrm{C}$ at $300{ }^{\circ} \mathrm{C}$. At first glance, such high $\delta T$ substantially limits the reliability of this measurement technique comparing to the thermocouple one, which usually has an average error of $10^{\circ} \mathrm{C}$ for the temperature range in question. However, that would be a hasty conclusion. The temperature field data across the series of experiments similar to those presented in Figure 4, we can conclude that an average temperature across the complete measurement period for the series in the thermocouple vicinity (Figure 4) does not deviate significantly (i.e., it does not exceed the contact technique error limits) from the thermocouple measurement. However, peak (maximum) temperatures in Figure 4 in different sections of the flow do exceed the average significantly. Such nuances could not be registered in thermocouple experiments for obvious reasons: long response time and limited number of thermocouples in use. 

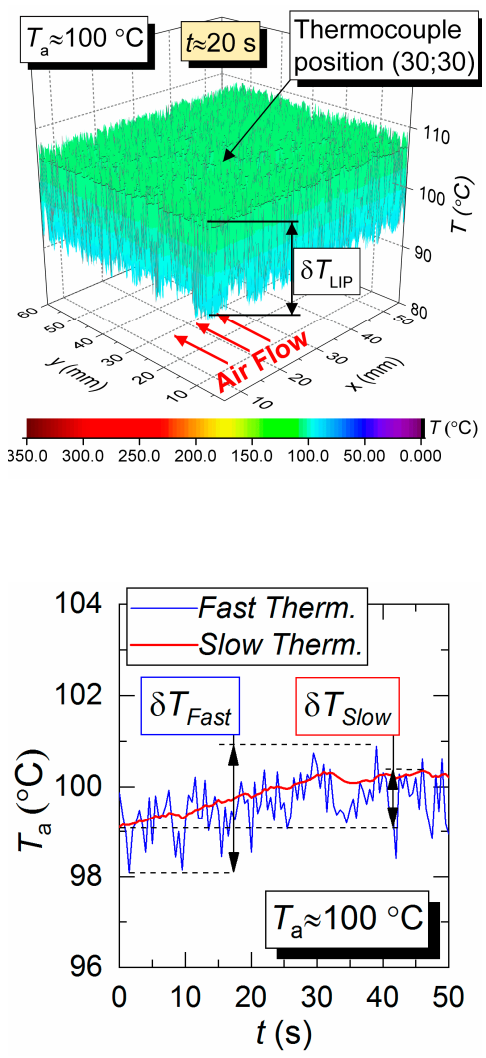

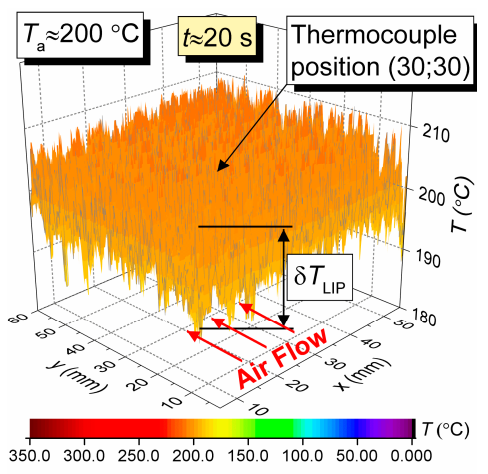

(a)

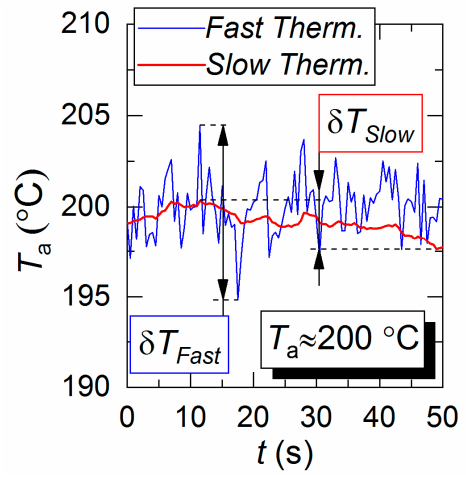

(b)
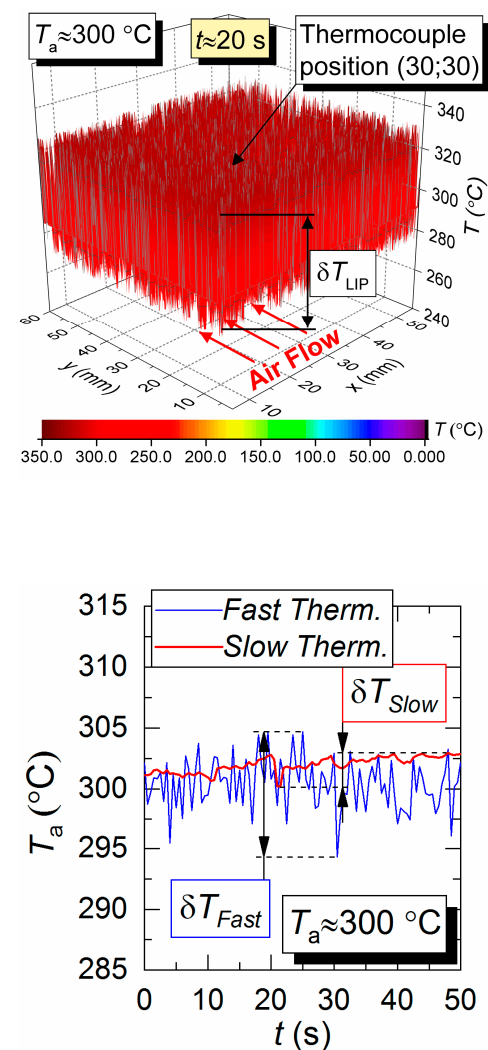

Figure 4. Temperature fields of the hot air flow (not blended with droplets) obtained by LIP (a), and temperature variation trends obtained by two types of thermocouples (b).

Figure $4 \mathrm{~b}$ shows the air flow temperature variation trends obtained by two types of thermocouple. The maximum deviations of the temperature recorded by a slow and a fast thermocouple (see Section 2.4 for specifications) from the average temperature measured by LIP are as follows; approximately $2{ }^{\circ} \mathrm{C}$ and $0.6{ }^{\circ} \mathrm{C}$ for $T_{\mathrm{a}}=100{ }^{\circ} \mathrm{C}$, approximately $8{ }^{\circ} \mathrm{C}$ and $1.5^{\circ} \mathrm{C}$ for $T_{\mathrm{a}}=200{ }^{\circ} \mathrm{C}$, and approximately $11^{\circ} \mathrm{C}$ and $2.3{ }^{\circ} \mathrm{C}$ for $T_{\mathrm{a}}=300^{\circ} \mathrm{C}$. A good correlation in general could be noted between the thermocouple and LIP measurements prior to droplet injection and when the gas temperature recovered after the droplets pass-through. Thus, the average air flow temperature deviation for all three cases does not exceed $3-5^{\circ} \mathrm{C}$.

Figure 5 shows temperature variation trends of gas-vapor mixture in the trace of a droplet flow, i.e., in the area of the air flow being passed through by droplets. The crosshatched area corresponds to the period of aerosol injection. All three measurement types are compared: two thermocouples and LIP technique. The thermocouple readings differ significantly from LIP measurement results during the period when the droplets pass through the temperature measurement area. The main difference is in the temperature peak values, number of these peaks, and periods between them.

It takes a slow thermocouple (Figure 5) quite a long time to recover the readings, namely, 30-40 s in our experiments. This result is apparently caused by the junction size of the slow type $\mathrm{K}$ thermocouple (Figure 2), which is 4 times bigger than that of the fast type $S$ thermocouple. More liquid settles on a large junction and its complete evaporation takes more time. Figure 5 demonstrates similarity between LIP measurement and fast thermocouple measurement during the temperature recovery period (after the droplets pass through). For a thorough comparative analysis of experimental data, 
parameters $\tau$ and $\Delta T_{\mathrm{a}}$ are calculated as well as the difference $(\Delta T)$ between LIP and fast thermocouple measurements (Figure 6a). $\Delta T$ was calculated as follows,

$$
\Delta T=\left|T_{\text {LIP }}-T_{\text {Therm }}\right|\left({ }^{\circ} \mathrm{C}\right) .
$$

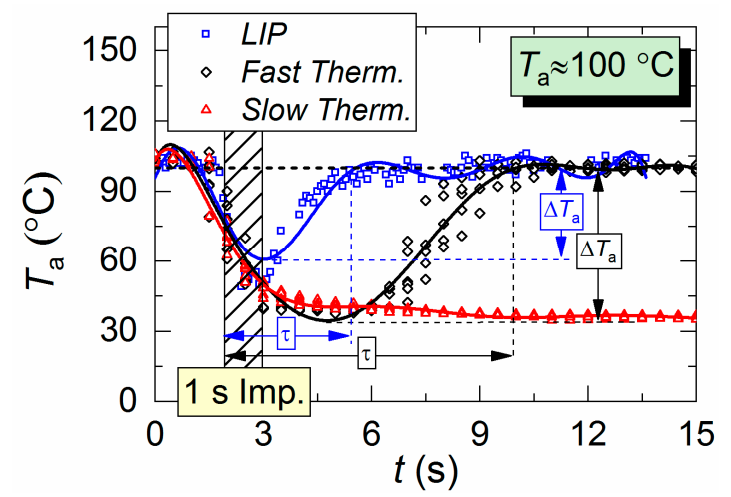

(a)

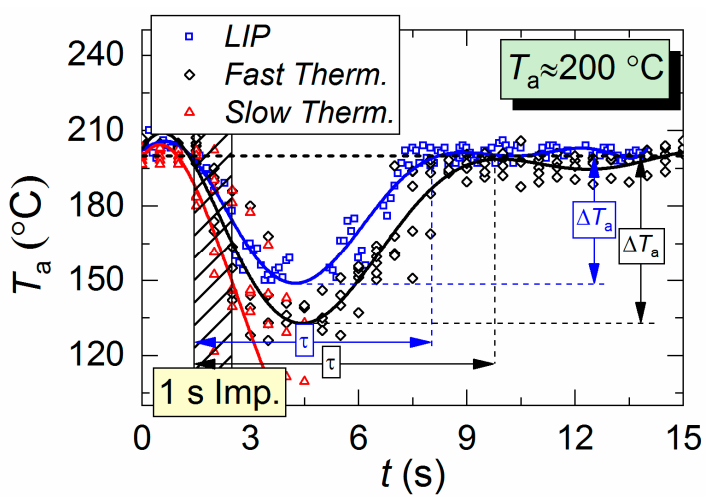

(c)

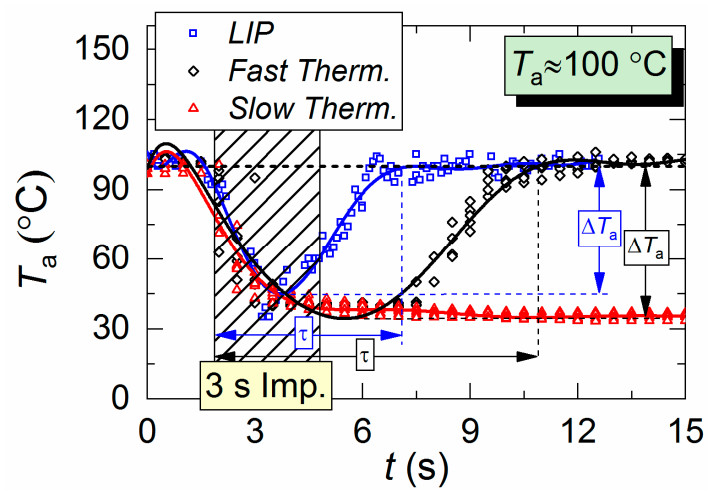

(b)

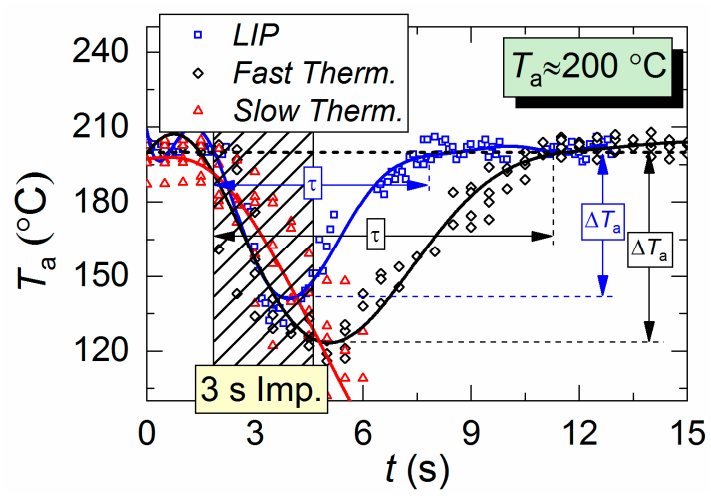

(d)

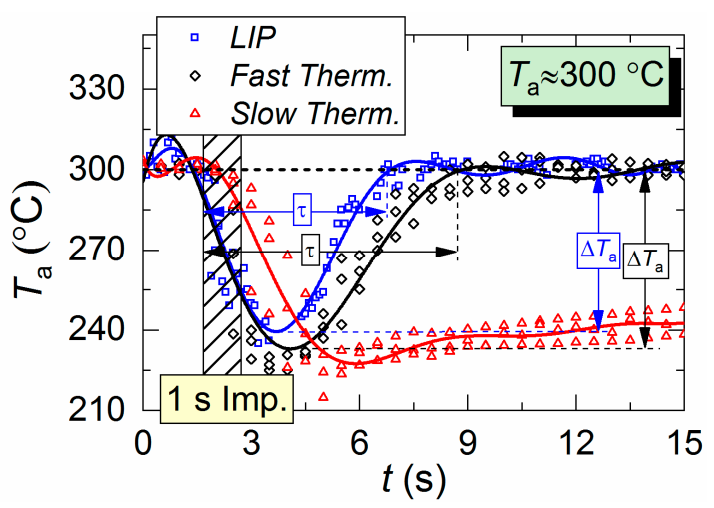

(e)

Figure 5. Air temperature variation in the trace of droplet flow during a single (1-3 s) injection of droplets: $(\mathbf{a}, \mathbf{b}) T_{\mathrm{a}} \approx 100{ }^{\circ} \mathrm{C} ;(\mathbf{c}, \mathbf{d}) T_{\mathrm{a}} \approx 200{ }^{\circ} \mathrm{C} ;(\mathbf{e}) \mathrm{T}_{\mathrm{a}} \approx 300{ }^{\circ} \mathrm{C}$.

Figure 6a clearly shows that the curves of the thermocouple measurements and LIP measurements differ significantly. Thus, $\tau$ and $\Delta T_{\mathrm{a}}$ for thermocouple measurements have almost no dependence on $t_{\mathrm{imp}}$ and $T_{\mathrm{a}}$. The same parameters for LIP measurement usually increase with the flow temperature growth. The maximum deviation between the two measurement techniques is observed at the flow temperature of $100{ }^{\circ} \mathrm{C}$ and it decreases with the further growth of $T_{\mathrm{a}}$. This allows us to conclude that 
lowered temperature readings during thermocouple measurement are caused only by thermocouple junction cooling and the delay of thermoelectric conversion. At the same time, lowered temperature readings during LIP measurement are caused by droplet evaporation in the gas environment. Water vapor in the observation area affects particle fluorescence (optical effect). The higher the initial gas environment temperature, the more noticeably the LIP readings are affected by vaporization. Moreover, the LIP measurements demonstrated quite an interesting result, for instance, with identical spray event duration (Figure 6a), the growth of the temperature of the flow increases the low temperature lifetime in its trace. Thus, at $t_{\mathrm{imp}} \approx 1 \mathrm{~s}$, the values of $\tau$ at $T_{\mathrm{a}} \approx 100{ }^{\circ} \mathrm{C}$ and $T_{\mathrm{a}} \approx 200{ }^{\circ} \mathrm{C}$ were approximately $3 \mathrm{~s}$ and $6 \mathrm{~s}$, whereas at $t_{\mathrm{imp}} \approx 3 \mathrm{~s}$, the values approximately $5.2 \mathrm{~s}$ and $5.5 \mathrm{~s}$, respectively. This result can be explained by the fact that the higher the $T_{\mathrm{a}}$ temperature, the higher the evaporation rates. That is to say, an increase in the flow temperature results in a higher mass of vapors injected into the recording area at each moment in time. This is indirectly confirmed by an increase in the maximum reduction of temperature, $\Delta T_{\mathrm{a}}$, with the growth of $T_{\mathrm{a}}$ (Figure 6a). Besides, Figure 6a also suggests that an increase in imp to $3 \mathrm{~s}$ does not considerably change $\tau$ and $\Delta T_{\mathrm{a}}$ at $T_{\mathrm{a}} \geq 200^{\circ} \mathrm{C}$. The obtained result is of great practical importance.
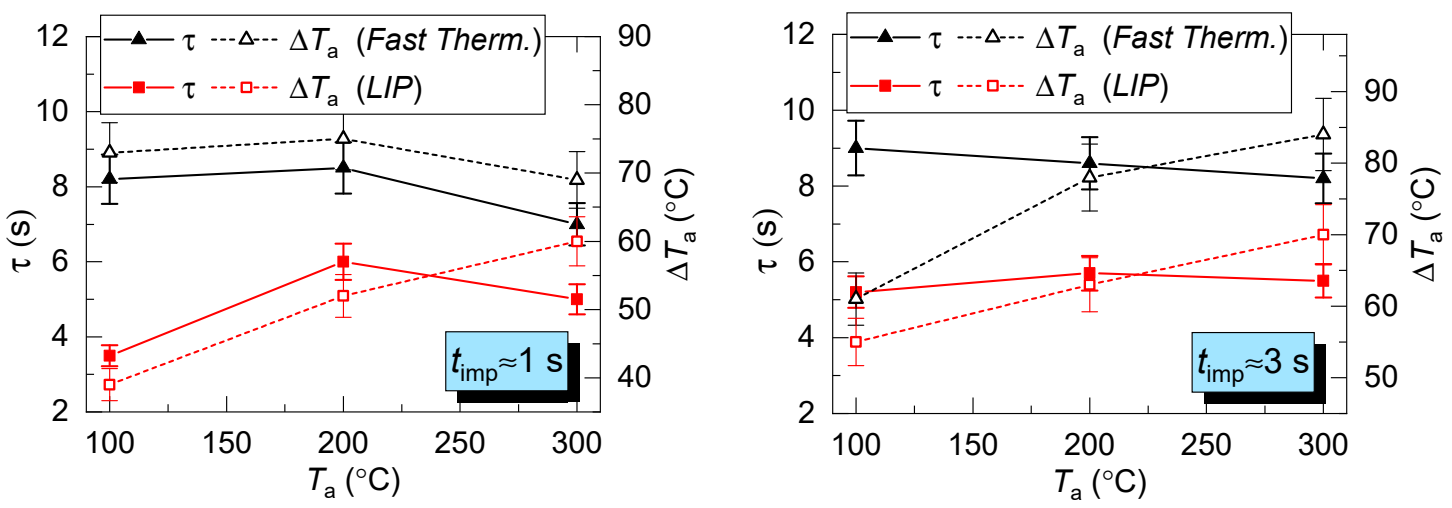

(a)

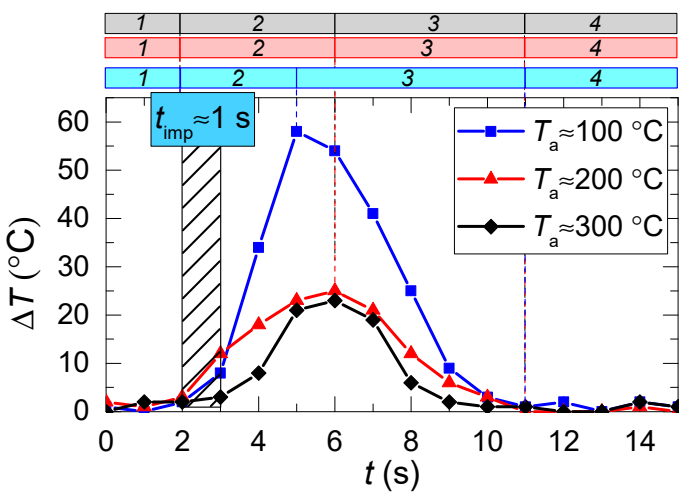

(b)

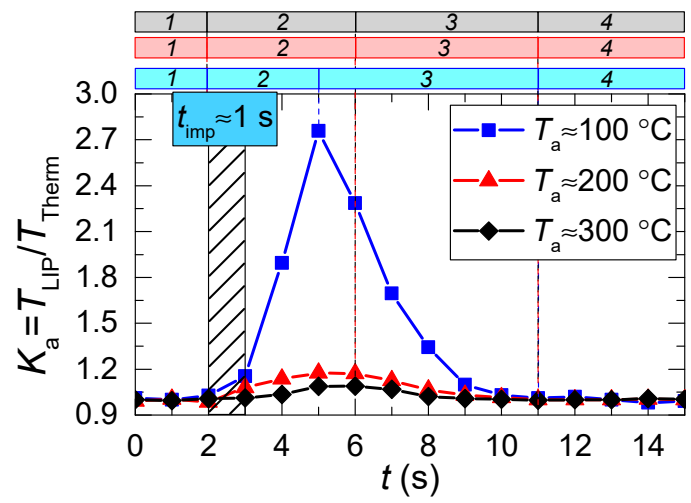

(c)

Figure 6. Parameters $\tau$ and $\Delta T_{\mathrm{a}}$ of heated air calculated for two measurement types (a); an example of instantaneous deviation $(\Delta T)$ of LIP measurement from thermocouple (Fast Therm.) measurement (b); coefficient $K_{\mathrm{a}}(\mathrm{c})$, areas per time period: 1: prior to droplet injection; 2: $T_{\mathrm{a}}$ temperature drop to the lowest value; 3: $T_{\mathrm{a}}$ temperature growth; $4: T_{\mathrm{a}}$ temperature recovery.

Several conclusions can be made from trend analysis in Figure $6 b, c$. First, the maximum difference of $\Delta T$ for the two measurement techniques lies in the range of 20 to $60{ }^{\circ} \mathrm{C}$ (area 3 in Figure $6 \mathrm{~b}$ ). Second, the recovery time of thermal trace $(\tau)$ derived from the measurement results varies by no 
more than $4.5 \mathrm{~s}$. Third, Figure 5 shows that, due to the thermal delay of the fast thermocouple immediately after the droplet injection, the flow temperature drop and subsequent recovery curve is much smoother (compared to LIP), meaning that the thermocouple significantly flattens the actual temperature variations. The LIP measurement displays a steep (substantial and fast) temperature drop with an equally steep subsequent recovery. That is why area 3 in Figure 6 is characterized by the maximum $\Delta T$ deviation. Readings from the second, much slower thermocouple have almost no correlation with the measurement results of LIP or fast thermocouple, because the droplet flow significantly cools down the larger junction. It takes much more time to recover (i.e., to heat the junction) to the initial temperature $T_{\mathrm{a}}$ with experimentally observed periods of 40 to $60 \mathrm{~s}$. As a result, it is possible to predict quite accurately the effect of this factor on the measurement fidelity in actual industrial applications.

\subsection{Combustion Products}

Figure 7 shows gas-vapor mixture temperature fields obtained by LIP measurement technique and temperature variation trends obtained by two different thermocouples for experiments with droplets and combustion products flow. Kerosene combustion products show much greater temperature fluctuation than the heated air flow (Figure 4). For example, $\delta T$ (Figure 7) for LIP technique is approximately $26^{\circ} \mathrm{C}$ for $T_{\mathrm{a}}=100^{\circ} \mathrm{C}$, approximately $44^{\circ} \mathrm{C}$ for $T_{\mathrm{a}}=200^{\circ} \mathrm{C}$, and approximately $109^{\circ} \mathrm{C}$ for $T_{\mathrm{a}}=300{ }^{\circ} \mathrm{C}$. This parameter for fast and slow thermocouples is approximately $43^{\circ} \mathrm{C}$ and $7{ }^{\circ} \mathrm{C}$ at $100{ }^{\circ} \mathrm{C}$, approximately $57^{\circ} \mathrm{C}$ and $5.5^{\circ} \mathrm{C}$ at $200{ }^{\circ} \mathrm{C}$, and approximately $88^{\circ} \mathrm{C}$ and $19.9^{\circ} \mathrm{C}$ at $300{ }^{\circ} \mathrm{C}$. The temperature fluctuations of combustion products are substantial for the whole duration of fuel combustion (due to combustion products flow turbulence). The temperature variations $(\delta T)$ for the LIP technique are significantly greater than those of the S-type thermocouple measurements due to the thermocouple response time. The thermocouple fails to record the peak variations of the gas-vapor mixture temperature in the observation area and, consequently, to provide a reliable calculated $\delta T$.
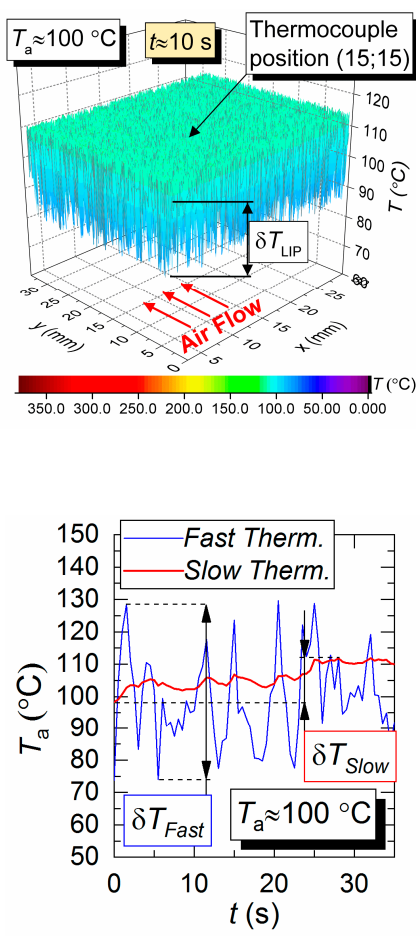

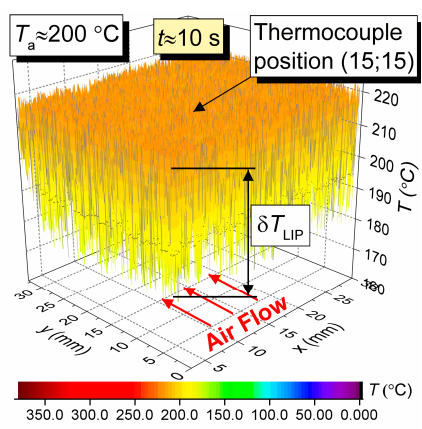

(a)

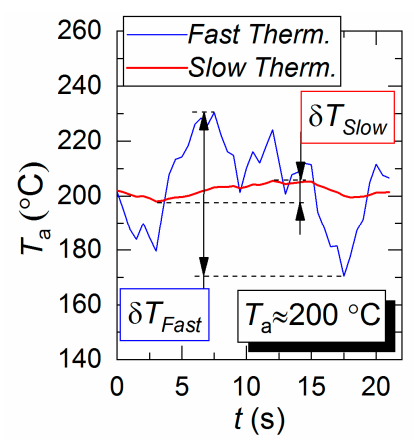

(b)
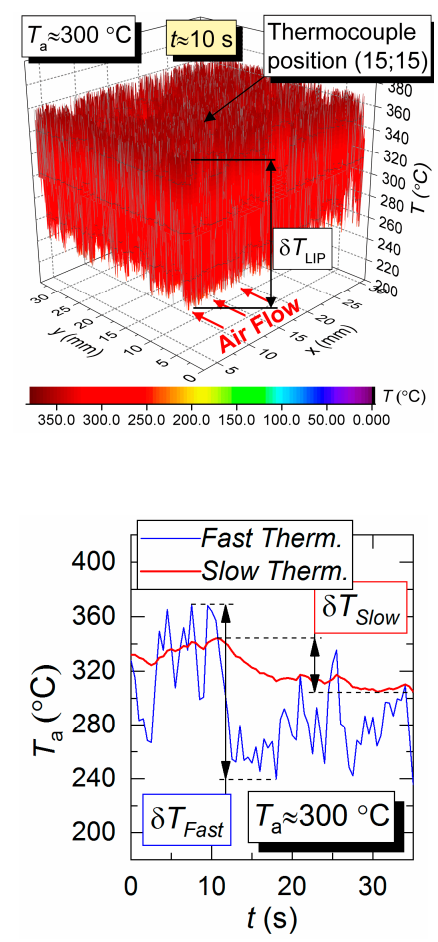

Figure 7. Temperature fields of combustion products flow (with no droplets present) obtained by LIP (a), as well as temperature variation trends obtained by two different thermocouples (b). 
When analyzing $\delta T$, LIP-measured temperature in the vicinity of thermocouple position was compared to the thermocouple readings. Due to a wide range of gas temperature variations in different sections of temperature field in Figure 7, $\delta T$ in those sections might differ significantly. This leads us to a conclusion that the thermocouple placement in the flow has a significant effect on the measurement results and on the difference from the LIP technique measurement results. This must be considered when contact and non-contact measurement results in experiments with combustion products.

Figure 8 shows the gas-vapor mixture temperature variation in the trace of a droplet flow. The results of all three measurements are compared: two thermocouples and LIP. In general, the LIP measurements are close to the fast thermocouple measurements. However, unlike in the heated air experiments (Figure 5), the LIP-measured temperature at its maximum drop is lower than the corresponding thermocouple readings, with up to $30-40{ }^{\circ} \mathrm{C}$ of difference. This must be because solid particles of the combustion products settle on the thermocouple junction. This may lead to an additional radiative heating of the junction. The thermocouple-measured temperatures are slightly higher than the actual ones. This conclusion is indirectly confirmed by temperature variation readings from the slow K-type thermocouple; the temperature is dropping slowly and monotonously, whereas the subsequent recovery is relatively fast (Figure 8), unlike in the case of heated air (Figure 5). Moreover, the fast temperature recovery of the slow thermocouple (Figure 8 ) is affected by the thermal radiation of combustion products. Therefore, the moisture that settled on the junction is heated and evaporates faster (Figure 5). This result allows us to conclude that reliable thermocouple measurements of temperature are possible under the conditions of lower gas-vapor mixture temperature and shorter injections of droplets.

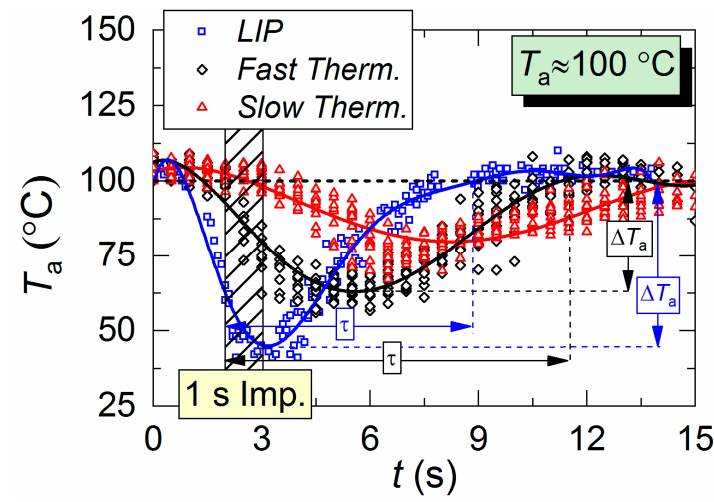

(a)

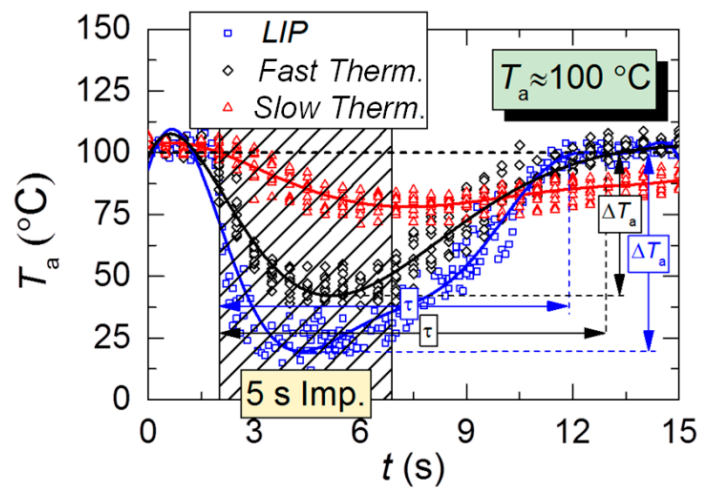

(c)

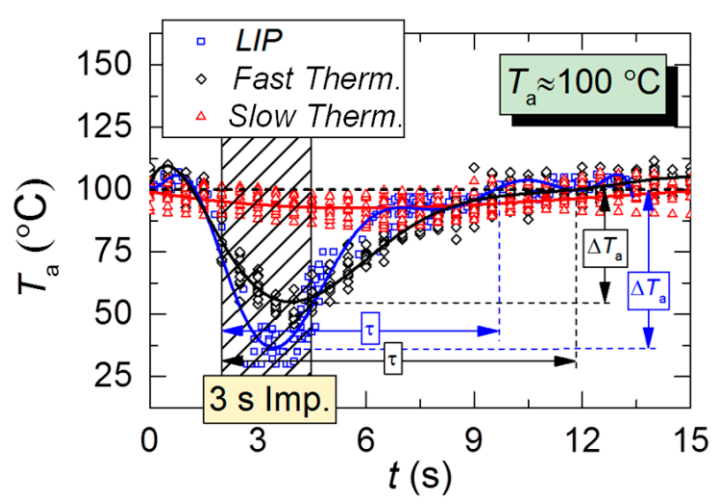

(b)

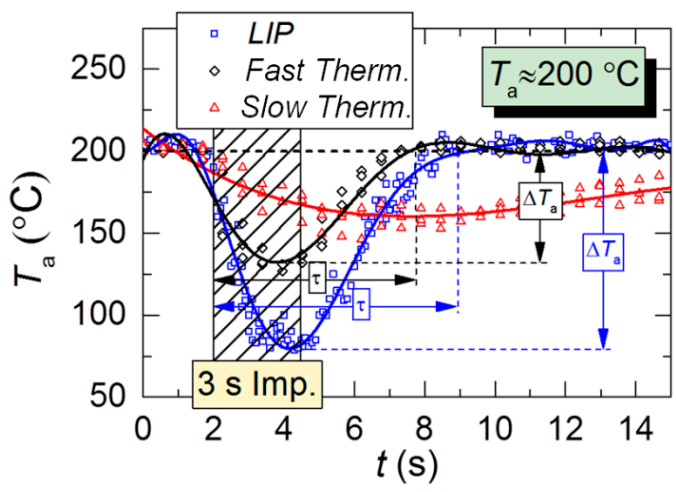

(d)

Figure 8. Temperature variations of kerosene combustion products with time in the trace of droplet flow for a single $1 \mathrm{~s}$ injection of droplets; initial air temperature: $(\mathbf{a}-\mathbf{c}) \mathrm{T}_{\mathrm{a}} \approx 100{ }^{\circ} \mathrm{C} ;(\mathbf{d}) \mathrm{T}_{\mathrm{a}} \approx 200{ }^{\circ} \mathrm{C}$. 
The comparison of Figures 5 and 8 shows that under identical initial experimental conditions, the $\tau$ and $\Delta T_{\text {a }}$ parameters in the combustion products are on average 1.5-2 times greater than in the heated air flow. There are several reasons for that. First, the additional release of energy due to the radiation of combustion products results in higher evaporation rates of droplets in this medium than in the air flow. This increases the mass of vapors injected into the gas medium. Second, a more turbulent flow, as compared with the air flow, captures and retains aerosol droplets, thus minimizing their escape outside the quartz channel. This also increases the total lifetime of droplets in the recording area and the duration of their evaporation.

Figure 9 shows the LIP measurement deviation from the fast thermocouple measurement. It is evident that at $T_{\mathrm{a}} \approx 100{ }^{\circ} \mathrm{C}$, overall the deviations are close to the corresponding results for the hot air flow (Figure 6). However, with an increase in the temperature of combustion products up to $T_{\mathrm{a}} \approx 200^{\circ} \mathrm{C}$, the deviation increases up to $85-90^{\circ} \mathrm{C}$.

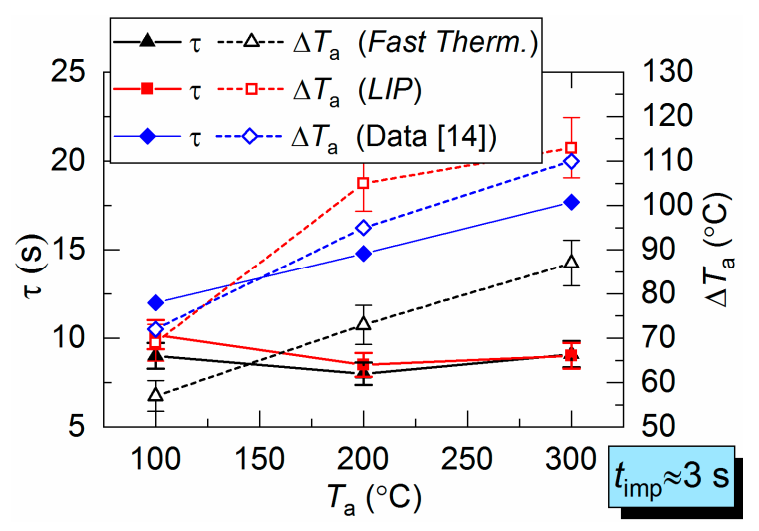

(a)

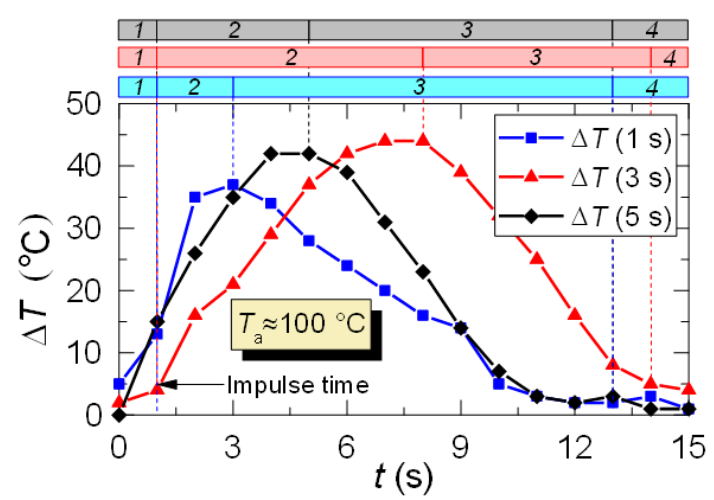

(b)

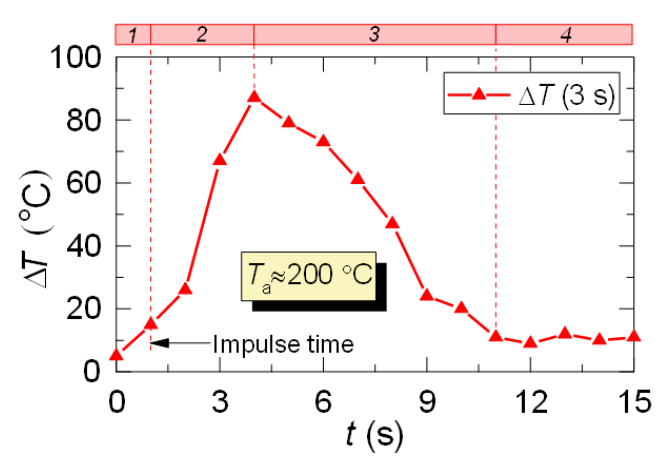

(c)

Figure 9. Parameters $\tau$ and $\Delta T_{\mathrm{a}}$ for combustion products flow obtained by two measurement techniques $(\mathbf{a})$, as well as difference $(\Delta T)$ between LIP measurement and fast thermocouple measurement: (b) $T_{\mathrm{a}} \approx 100{ }^{\circ} \mathrm{C}$; (c) $T_{\mathrm{a}} \approx 200{ }^{\circ} \mathrm{C}$ (1: prior to droplet injection; $2: T_{\mathrm{a}}$ temperature drop to the lowest value; 3: $T_{\mathrm{a}}$ temperature growth; $4: T_{\mathrm{a}}$ temperature recovery).

The lowered temperature lifetime $(\tau)$ is close for both LIP and thermocouple measurements and does not deviate for more than 1-3 s. This lifetime is in good agreement with experiments in [9-11]. However, it is important to note one important difference in $\tau$ recording results. The temperature fields plotted in this work allowed us to register the non-monotonic variation of all the main dimensions of the thermal traces and its lifetimes. It is highly difficult to register such occurrence using a single thermocouple or a small group thereof. The temperature fields obtained by LIP allow us to record this effect and to explain it by turbulence caused by counterflow blending of gas and droplet flows with different initial temperatures. 


\subsection{Adjustment and Generalization of Measurement Results}

After analyzing the thermocouple temperature results, we introduced coefficient $K$ with regards to the LIP results to adjust the thermocouple measurements. Coefficient $K$ is calculated as a ratio of LIP-measured temperature to thermocouple-measured temperature for each experimental point: $K=T_{\text {LIP }} / T_{\text {Therm }}$. Typical variations of $K$ are shown in Figure 10. From the results of the $K$ calculation, we can see its continuous variation with time. For all the experiments, deviation of $K$ from 1 is lower than $0.1-0.15$, that is, prior to droplet injection and after the temperature recovery (areas 1 and 4). This is due to the accuracy level of the LIP technique. The maximum $K$ is observed when the temperature recovers (rises) in the trace of the droplet flow (area 3, Figure 10), which is explained by the delay of the thermoelectric converter. It can be seen from Figure 10 that thermocouple measurements need to be adjusted at this very stage (area 3).
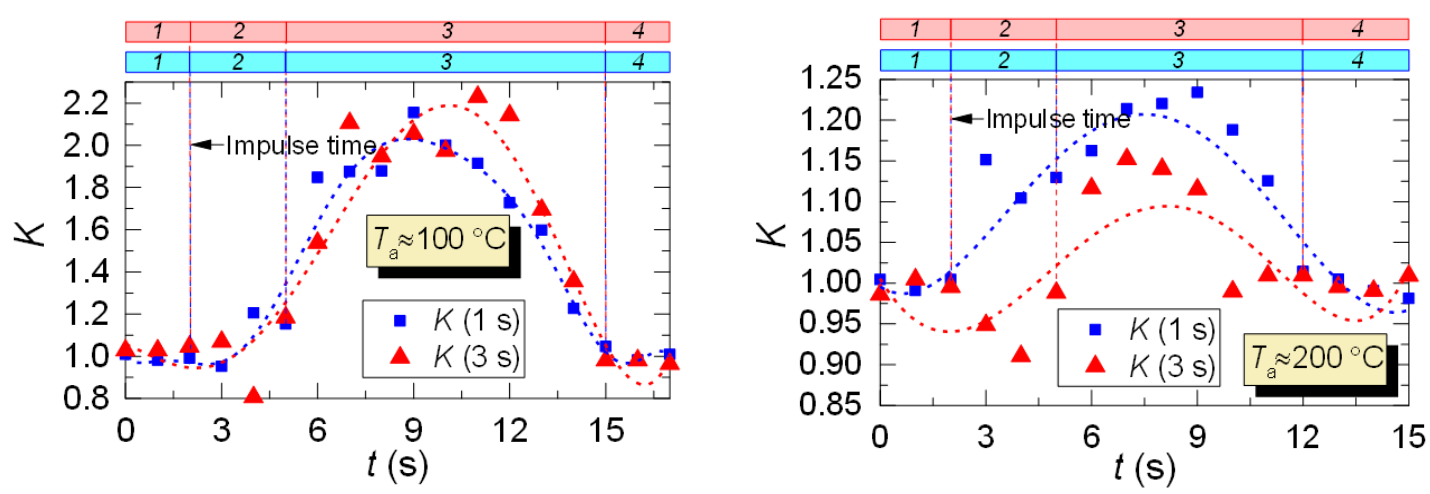

(a)
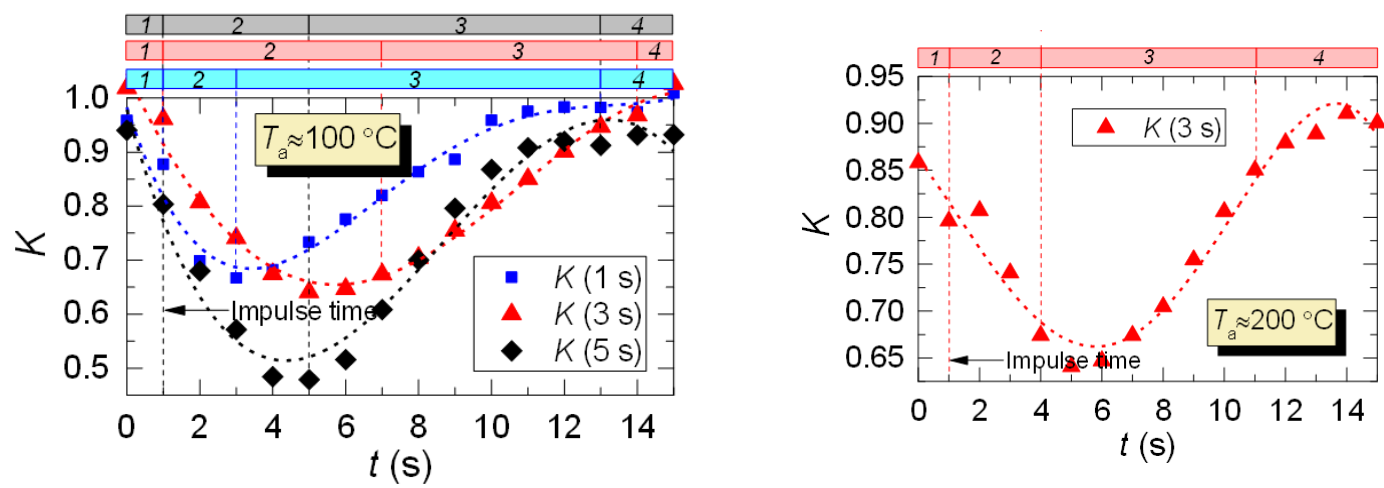

(b)

Figure 10. Variation of the adjusting coefficient $K$ in the trace of a droplet flow (1: prior to droplet injection; 2: $T_{\mathrm{a}}$ temperature drop to the lowest value; $3: T_{\mathrm{a}}$ temperature growth; $4: T_{\mathrm{a}}$ temperature recovery): (a) heated air flow; (b) kerosene combustion products flow.

For the case of heated air (Figure 10a), the adjustment leads to an increase in the temperature readings, and, consequently, to a slight (5-15\%) decrease in the maximum temperature fluctuations $\Delta T_{\mathrm{a}}$. The reverse is true for the case of combustion products flow (Figure 10b), when the actual temperature in the trace is lower than the thermocouple readings, and the adjustment increases $\Delta T_{\mathrm{a}}$ by $20-30 \%$. This effect is worth considering when predicting the maximum drop of the gas temperature in the trace of a gas-vapor-droplet flow.

Thus, with the help of coefficient $K$ we can adjust the readings of thermoelectric converters (make temperature readings closer to actual values) in cases when using non-contact measurement tools does not seem possible. 
Figure 11 shows the dimensionless lifetime of low temperature $\left(\tau / t_{\mathrm{imp}}\right)$ and the dimensionless gas-vapor-droplet mixture temperature in the trace of a droplet flow versus Reynolds number (Re calculated as in [21] considering droplet and gas flow velocity). The figure provides the LIP results and the experimental data from [21]. We can see the results from multiple experiments with thermocouples placed in different gas-vapor-droplet trace sections and taking into account the droplets cloud polydispersity.

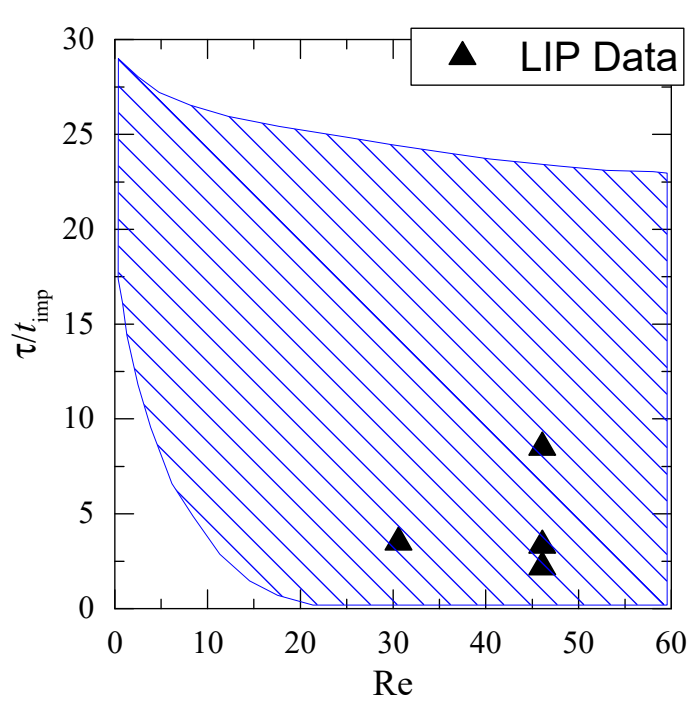

(a)

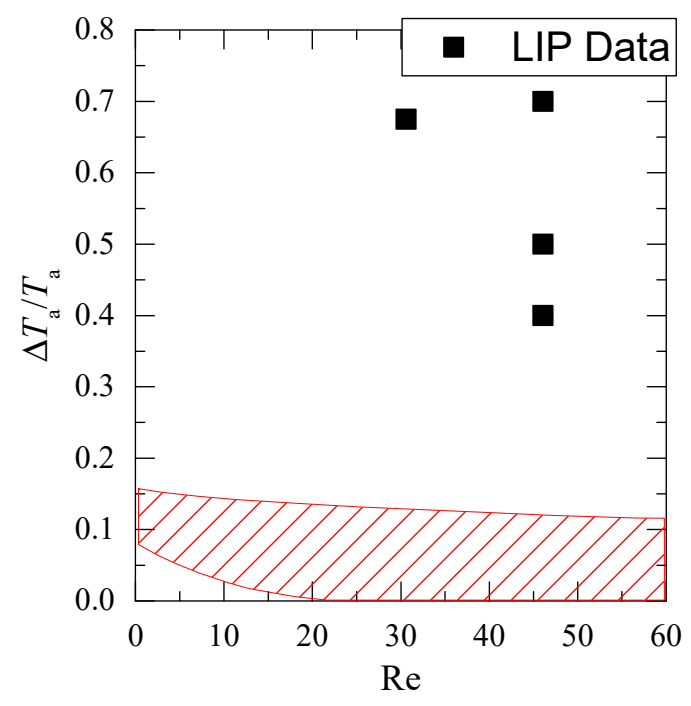

(b)

Figure 11. Dimensionless lifetime $\left(\tau / t_{\mathrm{imp}}\right)$ of the low gas temperature and relative temperature drop $\left(\Delta T_{\mathrm{a}} / T_{\mathrm{a}}\right)$ in the trace of droplets versus Re number (crosshatched area shows the data from the work in [21]): (a) dependence of $\tau / t_{\mathrm{imp}}=f(\operatorname{Re}) ;(\mathbf{b})$ dependence of $\Delta T_{\mathrm{a}} / T_{\mathrm{a}}=f(\operatorname{Re})$.

The generalization of our experimental results and data from [21] shows that complete recovery times of temperature fields after droplet and gas flow blending are very close (experimental data from contact and non-contact measurements correspond well in Figure 11a). The maximum temperature variation of the gas-vapor mixture differs significantly in Figure 11b. This result shows enough room for improvement of findings [21] in terms of exploring maximum (short-time peak values) gas-vapor mixture temperature variations that were difficult to record by thermocouples. This becomes possible with the application of non-contact recording techniques reviewed in the present work.

The gas-vapor-droplet technologies [35-43] use water-based solutions and emulsions as the operating fluid for the defrosting of granular materials, treatment of thermally loaded surfaces of power equipment, thermal or flame treatment of water, production of heat transfer fluids, firefighting, etc. One of the main problems when defining the parameters of all the above applications is the reliable prediction of droplets and vapor temperature and concentration. Using the technique presented in the present work, this can be achieved with high reliability and speed.

The results of this study are important for improving the performance of heat transfer technology in high-temperature high-speed applications (contact heat exchangers, thermal treatment chambers, and firefighting systems) due to higher measurement accuracy of gas-vapor mixture temperature. Accurate data from high-speed measurement is very important for emergency shut-down systems, as well as for efficient monitoring and control of operation parameters, i.e., temperature, heat release, thermal, and electric power generation. Simple prediction gives us roughly 20 to $60 \%$ of performance improvement for the applications mentioned above, if the measurement system obtains temperature readings fast and accurately in certain sections of the flow and records reliable unsteady inhomogeneous temperature fields in general. Temperature field data will provide for the advanced optimization 
of time and resource consumption. Decreasing the additive evaporation time in thermal treatment chambers by as little as $1-2 \mathrm{~s}$ will lead to consumption optimization by $20-40 \%$.

\section{Conclusions}

The unsteady temperature fields of the gas-vapor mixture give us insight into the comparative advantages and limitations of contact and non-contact measurement techniques. In particular, non-contact techniques proved to be more efficient in terms of the number of simultaneous measurement points, recording speed, peak temperature recording (both maximum and minimum), and the ability to conduct measurement under the condition of extensive phase transformations. LIP technique demonstrates substantial, albeit short-term, difference in the measurement results from thermocouple ones. In terms of the variation periods and peak temperatures (maximum and minimum), the difference may reach $60-80 \%$. The wider the temperature gradient in the area of droplet and gas flow blending, the greater the difference in temperature field readings from non-contact and contact measurement techniques. The defining role here belongs to the heat transfer between the thermocouple and the gas-vapor mixture, droplets in particular, later being the main elements of the blended environment.

Author Contributions: Investigation, R.S.V. and I.S.V.; writing-review and editing, R.S.V. and P.A.S. All authors have read and agreed to the published version of the manuscript.

Funding: Research was supported by Russian Science Foundation (project 18-79-00096).

Conflicts of Interest: The authors declare no conflicts of interest.

\section{Nomenclature and Units}

K

m

$n$

$R_{\mathrm{d}}$

$R_{\mathrm{dm}}$

$S^{*}$

$S_{0}$

$T_{\mathrm{a}}$

$t_{\text {imp }}$

$T_{\text {LIP }}$

$T_{\max }$

$T_{\text {min }}$

$T_{\text {Therm }}$

$U_{\mathrm{a}}$

$U_{\mathrm{d}}$

$V_{\mathrm{a}}$

$V_{\mathrm{m}}$

$x, y$

$\operatorname{Re}$

Greek

$\gamma_{\mathrm{d}}$

$\gamma_{\mathrm{p}}$

$\Delta T$

$\Delta T_{\mathrm{a}}$

$\delta T$

$\eta$

$\tau$

$\tau_{1}$

$\tau_{2}$ coefficient which is calculated as a ratio of LIP-measured temperature to

thermocouple-measured temperature for every experimental point: $K=T_{\mathrm{LIP}} / T_{\mathrm{Therm}}$;

number of droplet groups (for a single frame);

number of droplets in one group;

droplet radius, $\mathrm{mm}$;

mean radius of droplets in a group, $\mathrm{mm}$;

total area of BAM:Eu particles in a frame calculated by binarization threshold, $\mathrm{mm}^{2}$;

observation area size $\left(S_{0}=x \cdot y\right), \mathrm{mm}^{2}$;

gas flow temperature, ${ }^{\circ} \mathrm{C}$;

spray event duration, $\mathrm{s}$;

LIP-measured temperature, ${ }^{\circ} \mathrm{C}$;

temperature maximum, ${ }^{\circ} \mathrm{C}$;

temperature minimum, ${ }^{\circ} \mathrm{C}$;

thermocouple-measured temperature, ${ }^{\circ} \mathrm{C}$;

gas flow velocity, $\mathrm{m} / \mathrm{s}$;

droplet velocity, $\mathrm{m} / \mathrm{s}$;

notional volume of the observation area, $\mathrm{m}^{3}$;

average volume of droplets in a group, l;

width and height of the observation area, $\mathrm{mm}$;

Reynolds number.

droplet volume concentration in the sprayed flow, $1 / \mathrm{m}^{3}$;

dimensionless volume concentration of BAM:Eu particles in a frame;

difference between LIP measurement and fast thermocouple measurement, ${ }^{\circ} \mathrm{C}$;

combustion products or heated air temperature drop in the trace of droplet flow, relative to

its initial value, ${ }^{\circ} \mathrm{C}$;

maximum temperature deviation (fluctuation) $\left(T_{\max }-T_{\min }\right),{ }^{\circ} \mathrm{C}$.

thickness of the Nd:YAG laser sheet, $\mathrm{mm}$;

lowered temperature lifetime of combustion products in the trace of droplet flow, s;

start of combustion products temperature decrease, s;

complete time of combustion products temperature recovery to its initial value, s. 


\section{References}

1. Varaksin, Y. Fluid dynamics and thermal physics of two phase flows: Problems and achievements. High Temp. 2013, 51, 377-407. [CrossRef]

2. Sazhin, S.S.; Elwardany, A.E.; Krutitskii, P.A.; Deprédurand, V.; Castanet, G.; Lemoine, F.; Sazhina, E.M.; Heikal, M.R. Multi-component droplet heating and evaporation: Numerical simulation versus experimental data. Int. J. Therm. Sci. 2011, 50, 1164-1180. [CrossRef]

3. Hernández-Bocanegra, C.A.; Castillejos, A.H.; Acosta-Gonzalez, F.A.; Zhou, X.X.; Thomas, B.G. Measurement of heat flux in dense air-mist cooling: Part I-A novel steady-state technique. Exp. Therm. Fluid Sci. 2013, 44, 147-160. [CrossRef]

4. Sosnin, Y.P. Contact Water Heaters; Stroyizdat Publ.: Moscow, Russia, 1974.

5. Strizhak, P.A.; Volkov, R.S. The integral characteristics of the deceleration and entrainment of water droplets by the counter flow of high-temperature combustion products. Exp. Therm. Fluid Sci. 2016, 75, 54-65. [CrossRef]

6. Kuznetsov, G.V.; Kralinova, S.S.; Voytkov, I.S.; Islamova, A.G. Rates of high-temperature evaporation of promising fire-extinguishing liquid droplets. Appl. Sci. 2019, 9, 5190. [CrossRef]

7. Jiao, J.; Wang, Y.; Han, L.; Su, D. Comparison of water distribution characteristics for two kinds of sprinklers used for center pivot irrigation systems. Appl. Sci. 2017, 7, 421. [CrossRef]

8. Lieber, C.; Koch, R.; Bauer, H.-J. Microscopic imaging spray diagnostics under high temperature conditions: Application to urea-water sprays. Appl. Sci. 2019, 9, 4403. [CrossRef]

9. Kuznetsov, G.V.; Strizhak, P.A.; Volkov, R.S.; Vysokomornaya, O.V. Integral characteristics of water droplet evaporation in high temperature combustion products of typical flammable liquids using SP and IPI methods. Int. J. Therm. Sci. 2016, 108, 218-234. [CrossRef]

10. Volkov, R.S.; Strizhak, P.A. Motion of water droplets in the counter flow of high-temperature combustion products. Heat Mass Transf. 2017, 54, 193-207. [CrossRef]

11. Kuznetsov, G.V.; Strizhak, P.A.; Voytkov, I.S. Studying gas temperature variation upon aerosol injection. Technol. Phys. Lett. 2017, 43, 48-55.

12. Jones, J. Enhancing the accuracy of advanced high temperature mechanical testing through thermography. Appl. Sci. 2018, 8, 380. [CrossRef]

13. Allison, S.W.; Gillies, G.T. Remote thermometry with thermographic phosphors: Instrumentation and applications. Rev. Sci. Instrum. 1997, 68, 2615-2650. [CrossRef]

14. Khalid, A.; Kontis, K. Thermographic phosphors for high temperature measurements: Principles, current state of the art and recent applications. Sensors 2008, 8, 5673-5744. [CrossRef] [PubMed]

15. Chambers, M.D.; Clarke, D.R. Doped oxides for high-temperature luminescence and lifetime thermometry. Ann. Rev. Mater. Res. 2009, 39, 325-359. [CrossRef]

16. Volkov, R.S.; Kuznetsov, G.V.; Strizhak, P.A. Temperature and velocity fields of the gas-vapor flow near evaporating water droplets. Int. J. Therm. Sci. 2018, 134, 337-354. [CrossRef]

17. Peng, J.; Cao, Z.; Yu, X.; Yu, Y.; Chang, G.; Wang, Z. Investigation of flame evolution in heavy oil boiler bench using high-speed planar laser-induced fluorescence imaging. Appl. Sci. 2018, 8, 1691. [CrossRef]

18. Koegl, M.; Baderschneider, K.; Bauer, F.J; Hofbeck, B.; Berrocal, E.; Will, S.; Zigan, L. Analysis of the LIF/Mie ratio from individual droplets for planar droplet sizing: Application to gasoline fuels and their mixtures with ethanol. Appl. Sci. 2019, 9, 4900. [CrossRef]

19. Wittner, M.O.; Karbstein, H.P.; Gaukel, V. Pneumatic atomization: Beam-steering correction in laser diffraction measurements of spray droplet size distributions. Appl. Sci. 2018, 8, 1738. [CrossRef]

20. Kuznetsov, G.V.; Strizhak, P.A.; Volkov, R.S.; Voytkov, I.S. Gas temperature in the trace of water droplets streamlined by hot air flow. Int. J. Multiph. Flow 2017, 91, 184-193. [CrossRef]

21. Voytkov, I.S.; Volkov, R.S.; Strizhak, P.A. Reducing the flue gases temperature by individual droplets, aerosol, and large water batches. Exp. Therm. Fluid Sci. 2017, 88, 301-316. [CrossRef]

22. Simo Tala, J.V.; Russeil, S.; Bougeard, D.; Harion, J.-L. Investigation of the flow characteristics in a multirow finned-tube heat exchanger model by means of PIV measurements. Exp. Therm. Fluid Sci. 2013, 50, 45-53. [CrossRef]

23. Dehaeck, S.; Van Parys, H.; Hubin, A.; Van Beeck, J.P.A.J. Laser marked shadowgraphy: A novel optical planar technique for the study of microbubbles and droplets. Exp. Fluids 2009, 47, 333-341. [CrossRef] 
24. Charogiannis, A.; Beyrau, F. Laser induced phosphorescence imaging for the investigation of evaporating liquid flows. Exp. Fluids 2013, 54, 1518. [CrossRef]

25. Abram, C.; Fond, B.; Heyes, A.L.; Beyrau, F. High-speed planar thermometry and velocimetry using thermographic phosphor particles. Appl. Phys. B 2013, 111, 155-160. [CrossRef]

26. Linden, J. Laser Induced Phosphor Thermometry-Feasibility and Precision in Combustion Applications; Lund University: Lund, Sweden, 2012.

27. Lindén, J.; Takada, N.; Johansson, B.; Richter, M.; Aldén, M. Investigation of potential laser-induced heating effects when using thermographic phosphors for gas-phase thermometry. Appl. Phys. B 2009, 96, 237-240. [CrossRef]

28. Omrane, A.; Juhlin, G.; Ossler, F.; Alden, M. Temperature measurements of single droplets by use of laser-induced phosphorescence. Appl. Opt. 2004, 43, 3523-3529. [CrossRef]

29. Särner, G.; Richter, M.; Aldén, M. Two-dimensional thermometry using temperature-induced line shifts of $\mathrm{ZnO}: \mathrm{Zn}$ and $\mathrm{ZnO}: \mathrm{Ga}$ fluorescence. Opt. Lett. 2008, 33, 1327-1329. [CrossRef]

30. Brübach, J.; Patt, A.; Dreizler, A. Spray thermometry using thermographic phosphors. Appl. Phys. B 2006, 83, 499-502. [CrossRef]

31. Abram, C.; Fond, B.; Beyrau, F. Temperature measurement techniques for gas and liquid flows using thermographic phosphor tracer particles. Prog. Energy Comb. Sci. 2018, 64, 93-156. [CrossRef]

32. Lee, H.; Böhm, B.; Sadiki, A.; Dreizler, A. Turbulent heat flux measurement in a non-reacting round jet, using BAM: Eu2+ phosphor thermography and particle image velocimetry. Appl. Phys. B 2016, 122, 209. [CrossRef]

33. Zentgraf, F.; Stephan, M.; Berrocal, E.; Albert, B.; Böhm, B.; Dreizler, A. Application of structured illumination to gas phase thermometry using thermographic phosphor particles: A study for averaged imaging. Exp. Fluids 2017, 58, 82. [CrossRef]

34. Pope, R.M.; Fry, E.S. Absorption spectrum (380-700 nm) of pure water. II. Integrating cavity measurements. Appl. Opt. 1997, 36, 8710-8723. [CrossRef] [PubMed]

35. Terekhov, V.I.; Terekhov, V.V.; Shishkin, N.E.; Bi, K.C. Heat and mass transfer in disperse and porous media experimental and numerical investigations of nonstationary evaporation of liquid droplets. J. Eng. Phys. Thermophys. 2010, 83, 883-890. [CrossRef]

36. Dunand, P.; Castanet, G.; Lemoine, F. A two-color planar LIF technique to map the temperature of droplets impinging onto a heated wall. Exp. Fluids 2012, 52, 843. [CrossRef]

37. Labergue, A.; Delconte, A.; Castanet, G.; Lemoine, F. Study of the droplet size effect coupled with the laser light scattering in sprays for two-color LIF thermometry measurements. Exp. Fluids 2012, 52, 1121. [CrossRef]

38. Lemoine, F.; Castanet, G. Temperature and chemical composition of droplets by optical measurement techniques: A state-of-the-art review. Exp. Fluids 2013, 54, 1572. [CrossRef]

39. Snegirev, A.Y. Transient temperature gradient in a single-component vaporizing droplet. Int. J. Heat Mass Transf. 2013, 65, 80-94. [CrossRef]

40. Damiani, D.; Meillot, E.; Tarlet, D. A Particle-tracking-velocimetry (PTV) investigation of liquid injection in a dc plasma jet. J. Therm. Spray Technol. 2014, 23, 340-353. [CrossRef]

41. Misyura, S.Y. Evaporation and heat and mass transfer of a sessile drop of aqueous salt solution on heated wall. Int. J. Heat Mass Transf. 2017, 116, 667-674. [CrossRef]

42. Labergue, A.; Pena-Carillo, J.-D.; Gradeck, M.; Lemoine, F. Combined three-color LIF-PDA measurements and infrared thermography applied to the study of the spray impingement on a heated surface above the Leidenfrost regime. Int. J. Heat Mass Transf. 2017, 104, 1008-1021. [CrossRef]

43. Diddens, C.; Tan, H.S.; Lv, P.Y.; Versluis, M.; Kuerten, J.G.M.; Zhang, X.H.; Lohse, D. Evaporating pure, binary and ternary droplets: Thermal effect and axial symmetry breaking. J. Fluid Mech. 2017, 823, 470-497. [CrossRef]

(C) 2020 by the authors. Licensee MDPI, Basel, Switzerland. This article is an open access article distributed under the terms and conditions of the Creative Commons Attribution (CC BY) license (http://creativecommons.org/licenses/by/4.0/). 